Article

\title{
Bipolymeric Pectin Millibeads Doped with Functional Polymers as Matrices for the Controlled and Targeted Release of Mesalazine
}

\author{
Dorota Wójcik-Pastuszka ${ }^{\mathbb{D}}$, Aleksandra Potempa and Witold Musiał *(D) \\ Department of Physical Chemistry and Biophysics, Faculty of Pharmacy, Wroclaw Medical University, \\ ul. Borowska 211A, 55-556 Wroclaw, Poland; dorota.wojcik-pastuszka@umed.wroc.pl (D.W.-P.); \\ aleksandra.potempa@o2.pl (A.P.) \\ * Correspondence: witold.musial@umed.wroc.pl; Tel.: +48-71-78-40-231; Fax: +48-78-40-230
}

Academic Editors: Silvia Panzavolta and Luisa Stella Dolci

Received: 5 November 2020; Accepted: 1 December 2020; Published: 3 December 2020

Abstract: Targeted drug delivery systems are a very convenient method of treating inflammatory bowel disease. The properties of pectin make this biopolymer a suitable drug carrier. These properties allow pectin to overcome the diverse environment of the digestive tract and deliver the drug to the large intestine. This investigation proposed bipolymeric formulations consisting of the natural polymer pectin and a synthetic polymer containing the drug 5-aminosalicylic acid. Pectin beads were prepared via ionotropic gelation involving the interaction between the hydrophilic gel and calcium ions. The obtained formulations consisted of natural polymer, 5-aminosalicylic acid (5-ASA) and one of the synthetic polymers, such as polyacrylic acid, polyvinylpyrrolidone, polyethylene glycol or aristoflex. The release of the drug was carried out employing a basket apparatus (USP 1). The acceptor fluid was $\mathrm{pH}=7.4$ buffer with added enzyme pectinase to reflect the colon environment. The amount of the released drug was determined using UV-Vis spectrophotometry at a wavelength of $\lambda=330 \mathrm{~nm}$. The kinetics of the drug dissolution revealed that none of the employed models was appropriate to describe the release process. A kinetic analysis of the release profile during two release stages was carried out. The fastest drug release occurred during the first stage from a formulation containing pectin and polyethylene glycol. However, according to the applied kinetic models, the dissolution of 5-ASA was rather high in the formulation without the synthetic polymer during the second stage. Depending on the formulation, $68-77 \%$ of 5-ASA was released in an 8 -hour time period. The FTIR and DSC results showed that there was no interaction between the drug and the polymers, but interactions between pectin and synthetic polymers were found.

Keywords: mesalazine; drug release; kinetics; colon targeted drug delivery system

\section{Introduction}

Biopolymers such as pectin have been employed in various industrial fields including the pharmaceutical industry. The compounds have been proposed as drug carriers, particularly for targeted drug delivery. Biopolymers can be used as hydrogels, films and nanoparticles very easily. Pectin can overcome various environmental conditions, especially the low $\mathrm{pH}$ values in the stomach, and is digested by the microflora in the colon. Due to the properties of pectin, oral administration is the preferred method of its application [1]. Pectin formulations containing a drug can be used for colon-targeted drug delivery. The carrier is capable of protecting the drug, allowing it to reach the colon. Drug release and absorption do not take place in the stomach or in the small intestine [2]. The advantages of using natural polymers are their biocompatibility, nontoxicity and biodegradability [1].

Pectin is an anionic polysaccharide present in the cells of most plants [3]. It is mainly composed of linear chains containing $\alpha-(1 \rightarrow 4)$-D-galacturonic acid with carboxyl groups. The acid molecules 
are partially substituted with methyl ester or acetyl ester. For this reason, pectins are divided into the two groups of low or high methyl-esterified pectin, depending on the percentage of methylation of the carboxylic groups. Pectin containing a high amount of free carboxylic groups is defined as poly-anionic, low methyl-esterified pectin. The biopolymer can form a gel via cross-linking with calcium ions. The negatively charged carboxyl groups interact with the calcium ions. However, the type of pectin, its concentration and the cross-linking conditions influence the gel formation [4]. Hydrophobic interactions between the pectin chains and hydrogen bonding interactions between the amide groups contribute to the proposal of employing amidated low-methoxy pectins as very good natural polymers for bead formation [5].

The disadvantages of using pectin beads for drug delivery applications are related to the decomposition of the beads and the difficulty of controlling the release of the drug [6]. On the other hand, the synthetic polymers are intensively developed for pharmaceutical applications. The newly synthetized polymers may constitute a matrix for controlled delivery of variety of bioactive molecules, including cytostatics and other medicinal substances [7-9].

Compound 5-ASA (5-aminosalicylic acid, mesalazine) is the therapeutically active moiety in the treatment of inflammatory bowel disease. However, plain mesalazine is completely absorbed in the upper part of the intestine. Therefore, pharmaceutical formulations have been designed that can carry mesalazine undisturbed through the stomach, the duodenum and the proximal jejunum to deliver high concentrations of 5-ASA to the targeted inflammatory sites of the distal small intestine and colon $[10,11]$.

Although several investigations on pectin beads containing the drug have been reported [12-18], a study on pectin formulations containing synthetic polymers is not found in the literature.

The aim of this study is to propose a formulation of pectin beads containing a synthetic polymer for colon-targeted drug delivery and to evaluate the release kinetics of the drug from the carriers. The incorporation of the synthetic polymer into the pectin formulation may overcome the difficulties associated with the fast decomposition of pectin beads and may prolong the release of the drug.

\section{Results and Discussion}

\subsection{Morphological Studies}

The picture of obtained millibeads doped with synthetic polymers before drying were illustrated in Figure 1. The images of all formulations are presented in supplementary materials in Figure S1.
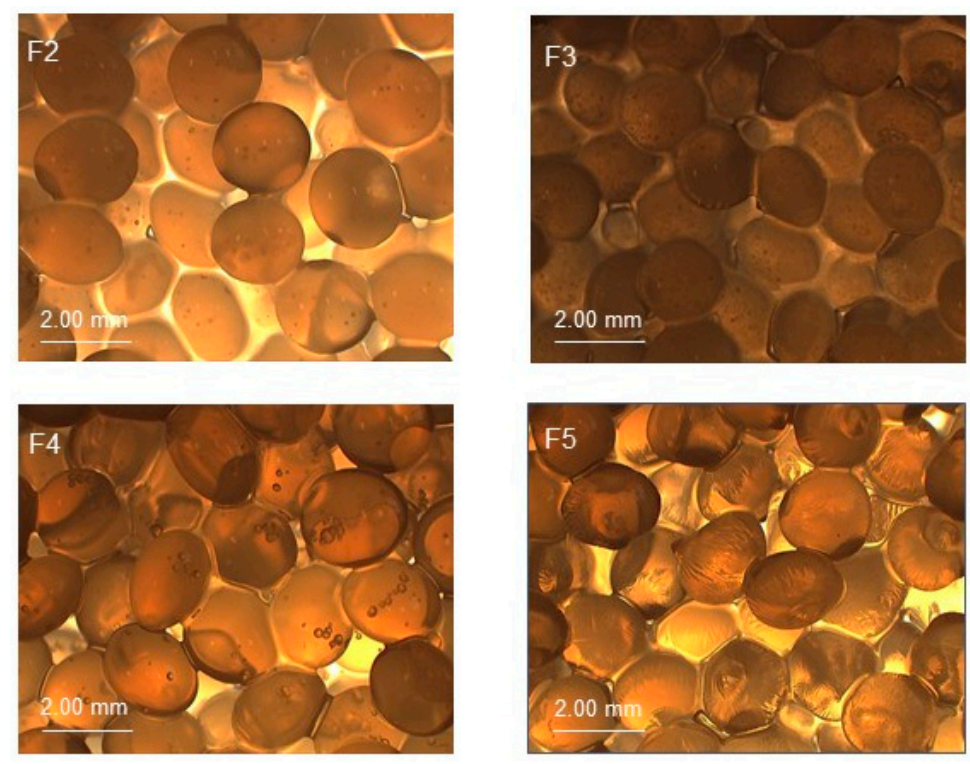

Figure 1. The microscopic pictures of millibeads F2-F5 unloaded with 5-ASA. 
The obtained results of the mean diameter of the dry and wet formulations F1-F10 are shown in Figure 2.

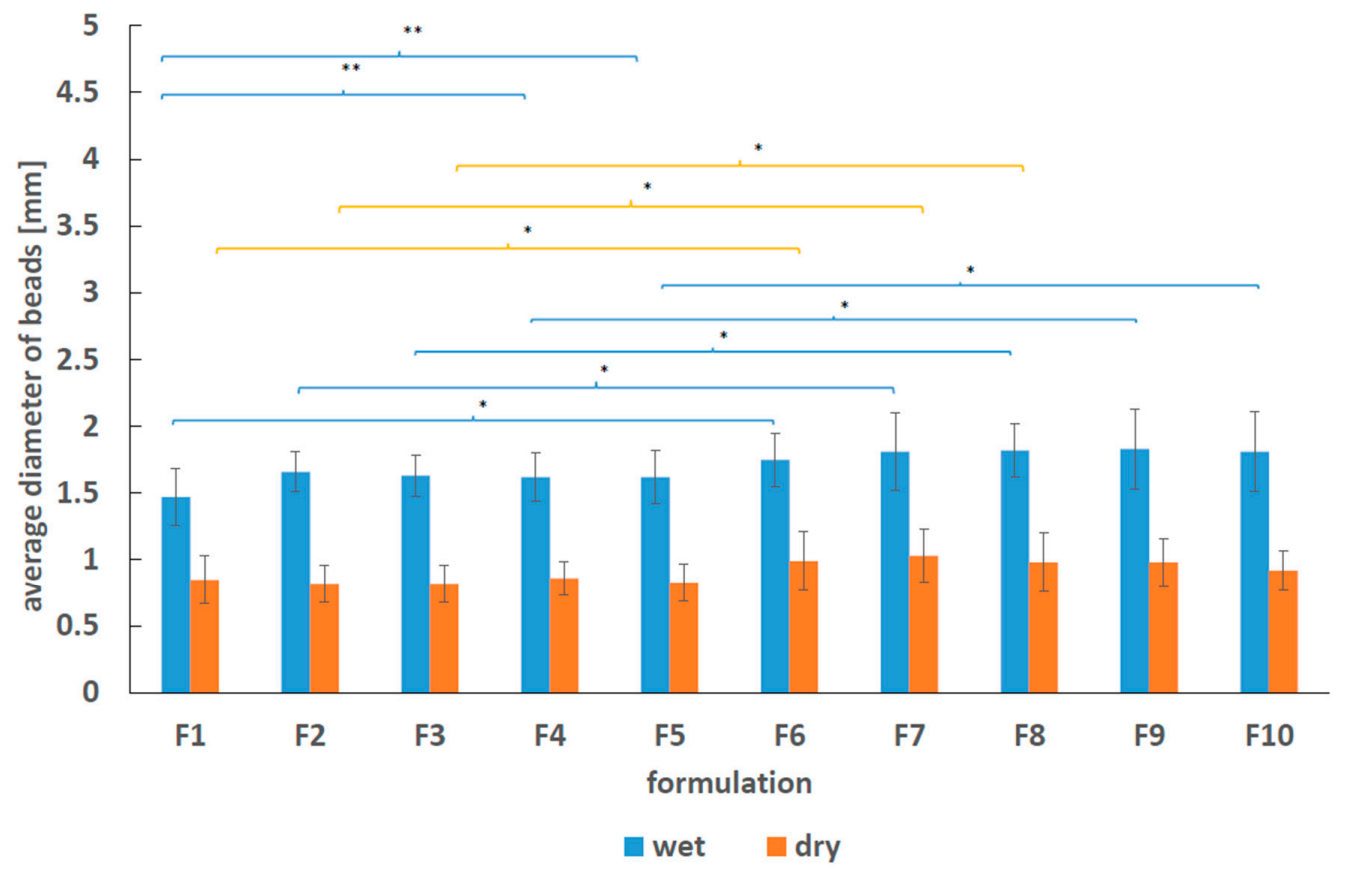

Figure 2. The average diameter of beads before and after drying. Significant differences between average diameter of beads, $p<0.05$ (described by * for the influence of 5-ASA component, and by ** for the influence of the incorporation of synthetic polymer).

Produced millibeads had spherical morphology, however the transparency was slightly different, what may implicate variability in the density, as well as light absorbance. The superficial morphology of the beads was smooth and they were resilient. The observed discrepancies of diameters of produced beads may be ascribed to the repulsive bonds between polymers. The interactions between chains may have the impact on the release of the drug due to steric hindrances of long polymeric chains. The diameters of the wet formulations ranged from $1.47 \pm 0.21 \mathrm{~mm}$ to $1.83 \pm 0.30 \mathrm{~mm}$ and were significantly higher than the diameters of the dry beads that were in the range from $0.82 \pm 0.14 \mathrm{~mm}$ to $1.03 \pm 0.20 \mathrm{~mm}$. This difference was mainly related to the water loss that occurs during drying.

The variability of bipolymeric beads diameters was analysed employing ANOVA combined with Tukey's honest significant difference test (Tukey's HSD test) and the statistical results are listed in Tables S1 and S2 attached in supplementary materials. The values of mean diameter of wet and dry beads was also presented in supplementary materials in Table S3. It was found that the mean values of the diameters of wet formulations F1-F5 were different from the mean values of the diameters of wet formulations F6-F10 loaded with 5-ASA. In the case of dry beads, the mean values of the diameters of formulations F1-F3 were slightly lower than the values obtained for formulations F6-F8. The differences can be explained by the incorporation of 5-ASA into formulations F6-F10. The dry F9-F10 beads did not changed the diameter comparing to the diameter of the beads unloaded with 5-ASA. The comparison of the mean diameters of the beads F1, and the mean diameters of the formulations containing synthetic polymers F2-F5 gave no substantial difference between the wet and dry preparations, although ANOVA test indicated the difference between wet F1 and F4, F5 millibeads. Comparing the mean diameters of F6 beads and F7-F10 doped with synthetic polymers the differences were not observed in the case of wet as well as dry formulations F7-F10. The incorporation of AX and PEG increased only wet beads diameters unloaded with 5-ASA. 


\subsection{Drug Release Study}

The drug was released into a $\mathrm{pH}=7.4$ buffer solution with pectinase that reflected the fluids in the colon [19]. The stability of pectin carriers F1-F5 in $\mathrm{pH}=1,6.0$ and 7.4 with pectinase conditions simulating the gastric environment of gastrointestinal tract (GIT) was studied, and the results are shown in Figure 3.

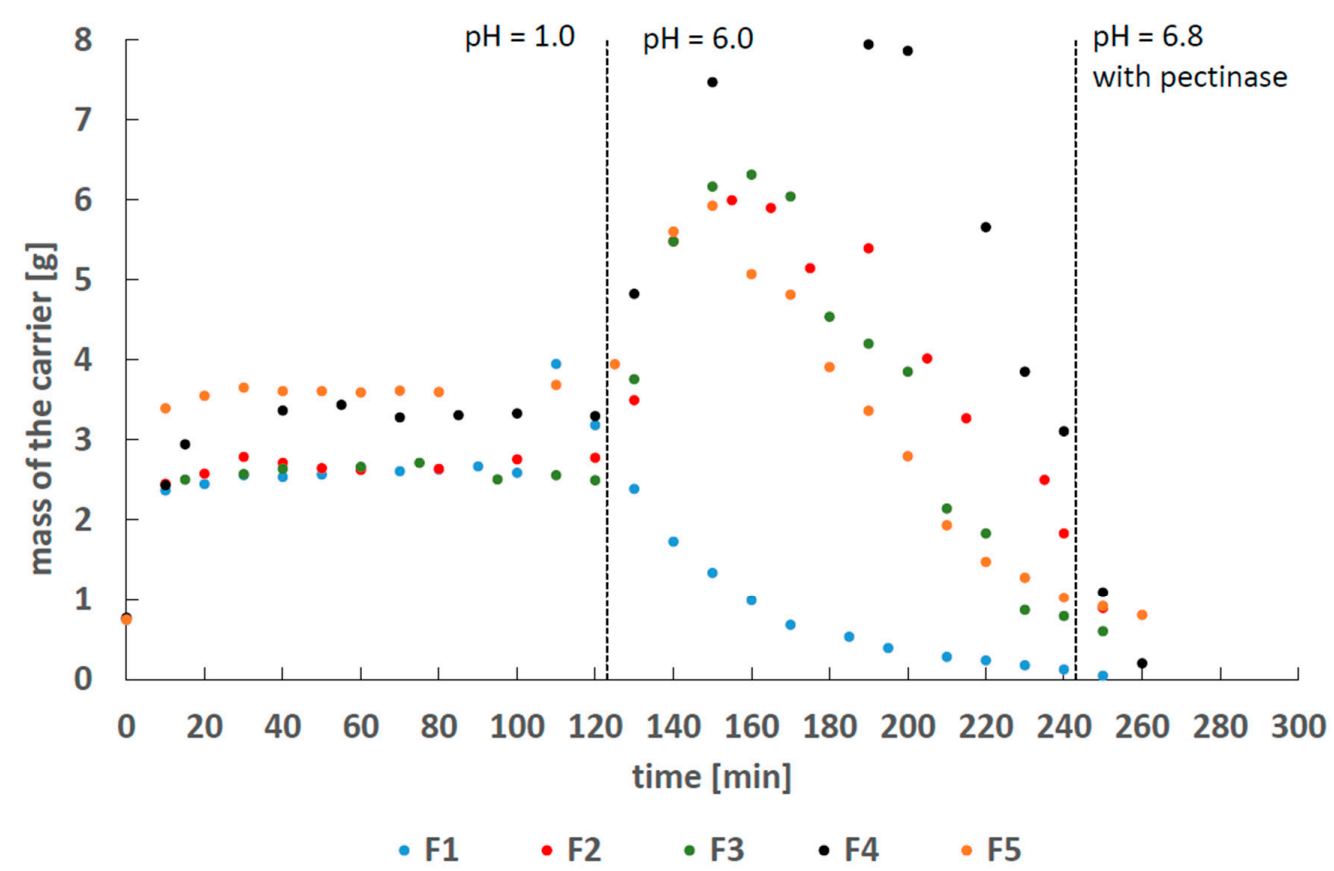

Figure 3. The mass variability of the carrier in time, in the solution of $\mathrm{pH}=1, \mathrm{pH}=6.0$ and $\mathrm{pH}=7.4$ with pectinase.

The acidic environment did not influence the decomposition of the pectin carrier. The observed initial increase in the matrix weight was caused by the penetration of water into the bead interior. These results suggest that pectin carriers can overcome the acidic stomach environment and reach the colon. The carriers decompose in the presence of an alkaline environment and intestinal bacteria. The disintegration of the carrier may then cause the release of the drug.

Several kinetic models, which are listed in Section 4.5, were used in the drug dissolution study. It was found that neither of the employed equations was appropriate to describe the dissolution profiles of 5-ASA in the 8-hour time period. The dissolution of the drug from the studied formulations was very fast at the beginning, followed by sustained drug release. The obtained release curves are shown in Figure 4.

The dried beads immersed in the acceptor fluid swelled during the initial stage, after which their volume became constant. This observation combined with the concentration gradient of the drug between the beads and the acceptor fluid could explain the characteristic release profile of 5-ASA from formulations F6-F10. The influence of the drug concentration gradient on the release was confirmed by the results obtained from the K-P equation. The derived values of the parameter $n$ were below 0.5 in most cases, indicating that the mass transport occurred via diffusion. The value of $n$ was $0.65 \pm 0.08$ only in the case of drug release from formulation F7, suggesting anomalous transport [20]. The results are consistent with results obtained by Shen et al. [21]. Their work revealed that the initial drug release was very fast, followed by a sustained drug release. This release pattern was explained by the electrostatic interaction between the drug and matrix as well as the concentration variability between the formulation interior and the bulk. 


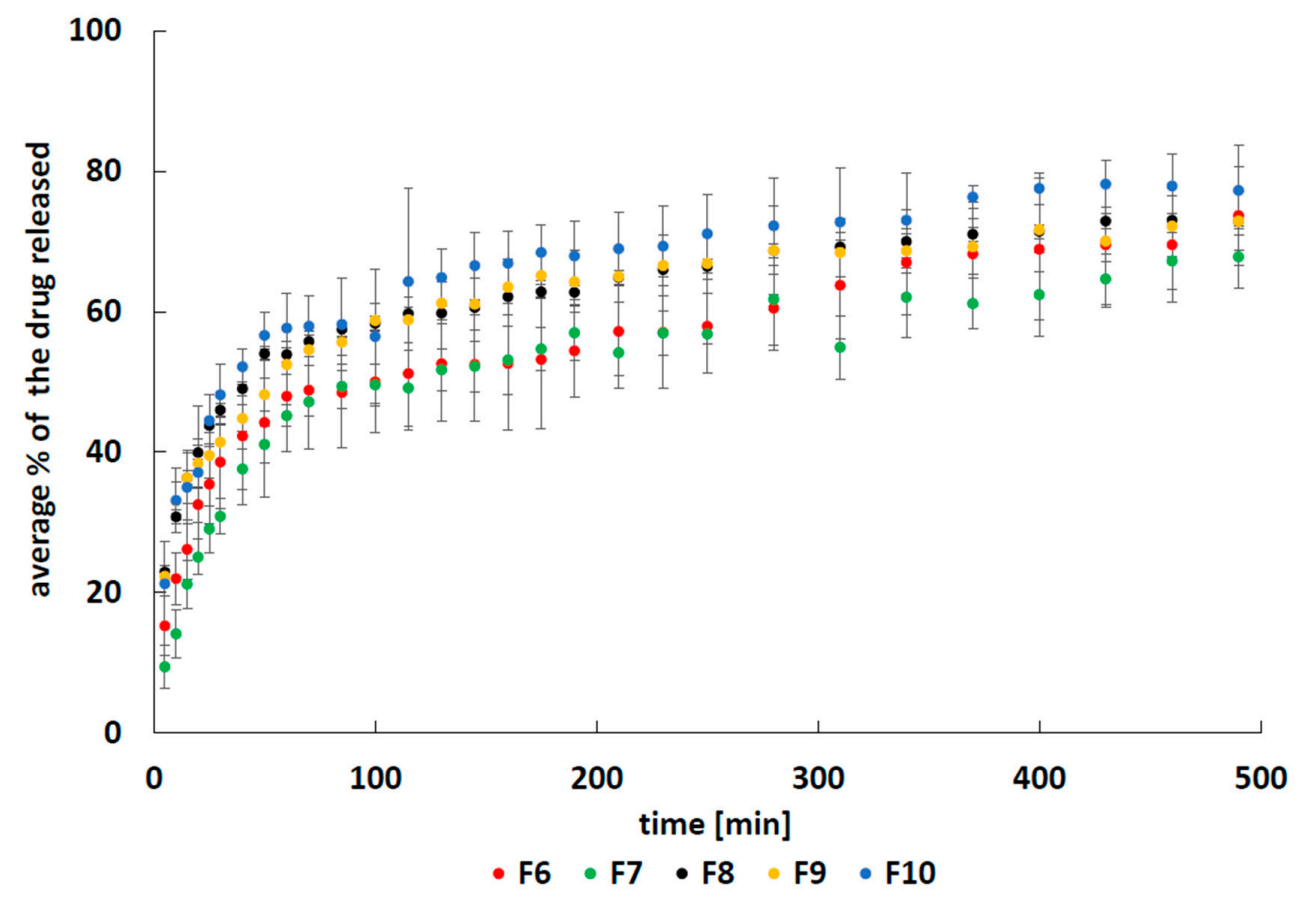

Figure 4. The release curves of 5-ASA from formulations F6-F10.

To carry out the kinetic analysis of the release of 5-ASA, the obtained dissolution profiles were divided into two stages. The first stage included the drug release as well as matrix swelling. The second stage contained only the dissolution of the drug. An example of fitting the experimental data of the release of 5-ASA from formulation F8 to the kinetic equations is shown in Figure 5. Based on this analysis, the kinetic parameters were derived, and they are listed in Tables 1 and 2. Considering the values of the correlation coefficient $\mathrm{R}^{2}$, it was found that the first stage of the release of 5-ASA from formulations F6-F10 was mainly described by the Korsmeyer-Peppas or by the second-order kinetic models. The highest release rate constants calculated for this stage using the F-O, S-O, $\mathrm{H}$ and $\mathrm{H}-\mathrm{C}$ equations were obtained for the release of 5-ASA from formulation F10. The shortest half release time was obtained for the 5-ASA release from formulation F10. The lowest $t_{0.5}$ value was obtained from the K-P model for the drug release from formulation F8, and the highest value of the release rate constant was obtained for 5-ASA release from formulation F9. Summarizing these results, it can be concluded that the incorporation of the synthetic polymer into the formulation did not significantly prolong the release of 5-ASA from pectin beads during the first stage of the release. This may be explained by the dissolution of the drug from the surface immediately after immersion in the acceptor fluid.

The second stage of the release of 5-ASA from the studied formulations cannot be analyzed by the K-P model. This equation may be used only when $\mathrm{m}_{\mathrm{t}} / \mathrm{m}_{\infty}<0.6[20,22]$. According to the $\mathrm{Z}-\mathrm{O}, \mathrm{F}-\mathrm{O}, \mathrm{H}, \mathrm{H}-\mathrm{C}$ kinetic models, the fastest 5-ASA release during second stage was observed for formulation F6, which did not contain the synthetic polymer. The fastest 5-ASA dissolution was observed for formulation F10 when the S-O equation was used, although the difference between the $\mathrm{k}_{2}$ values obtained for the drug release from formulations F10 and F6 was not large. The $\mathrm{k}_{2}$ values were $1.4 \pm 0.4 \mathrm{mg}^{-1} \mathrm{~min}^{-1}$ and $1.2 \pm 0.2 \mathrm{mg}^{-1} \mathrm{~min}^{-1}$ for the drug release from F10 and F6, respectively. The half release time was also the shortest for the dissolution of the drug from formulation F6. However, when the S-O equation was used, the shortest half release time was observed for the 5-ASA release from formulation F10. There was no substantial difference between the $t_{0.5}$ obtained for the drug release from formulations F6 and F10. The $t_{0.5}$ values for the drug release from F6 and F10 were $413.0 \pm 69.0$ min and $381.8 \pm 130.5 \mathrm{~min}$, respectively. These results suggest that incorporation of the synthetic polymers into the pectin beads prolonged the release of the drug. The mass transfer in formulation F6 that did not contain the second polymer was more efficient than the mass transfer in formulations F7-F10 with 
a high density of polymer chains hindering drug migration. The daily therapeutic dose of 5-ASA in the range of 1.5-4.5 $\mathrm{g}$ was applied in the active ulcerative colitis [23], and doses may be higher according to developed dosing schemes [24]. In the presented study, the level of 5-ASA used in one release test was $500 \mathrm{mg}$. The proposed dosing system is thus suggested to be used 3 times a day. Prospectively, the dosing may be increased to double the administered value of 5-ASA to $1000 \mathrm{mg}$. This form of the drug appears to be acceptable for patients with swallowing difficulties. The multi-compartmental form of the preparation may enable protection against an undesired increase in the drug concentration in the case of partial damage of coatings, as the dose was divided into tiny doses. The higher doses will be further developed. The release at $1.0 \mathrm{pH}$ should be performed in further studies, to exclude enhanced loss of 5-ASA in gastric fluid in the preliminary phase of release. The resulting formulations after respective evaluation will be proposed for further in vivo experiments to evaluate the prospective clinical efficacy.
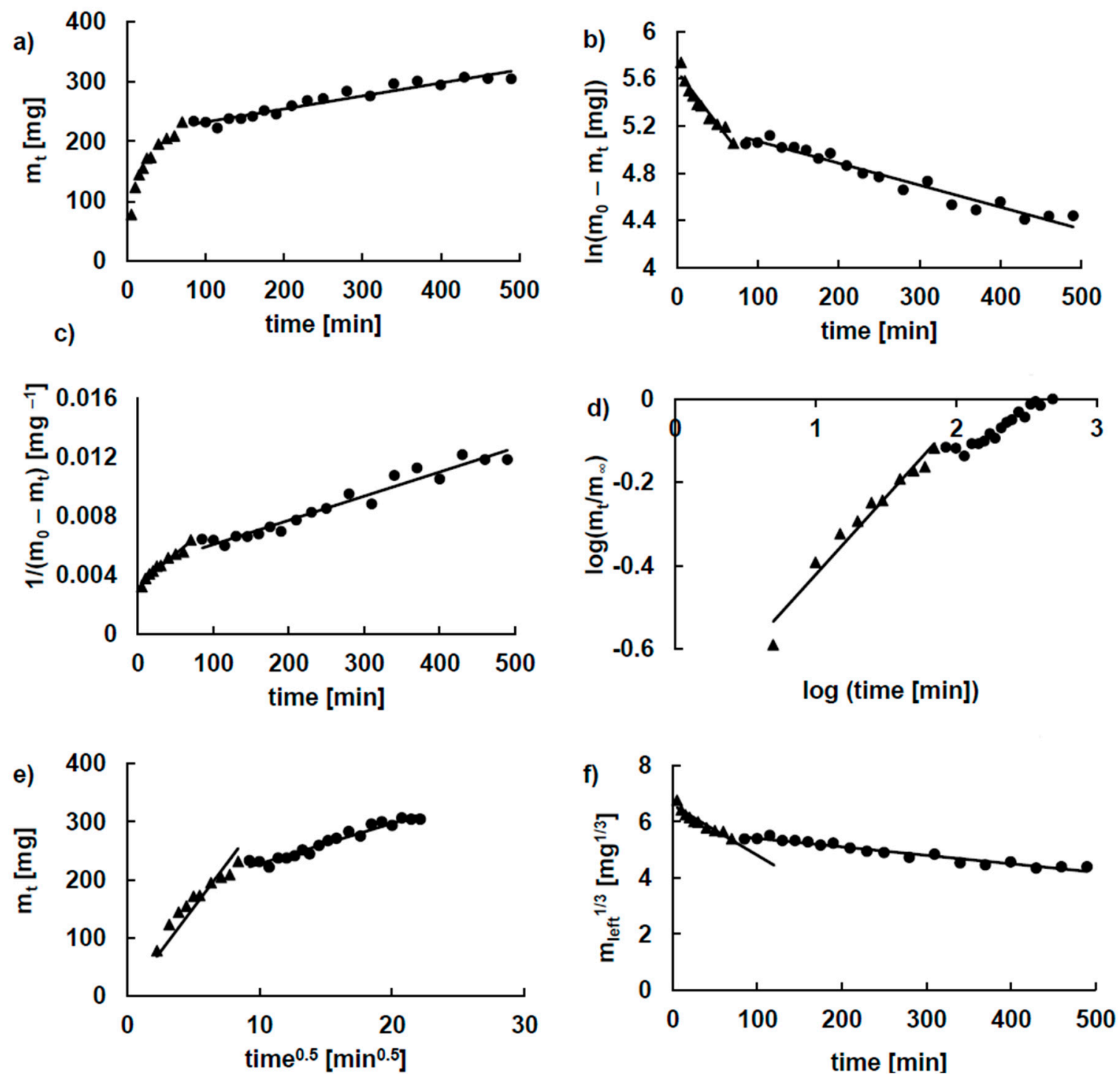

Figure 5. Kinetics of the release of 5-ASA from formulation F8 according to (a) zero-order, (b) first-order, (c) second-order, (d) Korsmeyer-Peppas (e) Higuchi (f) Hixon-Crowell model; experimental points of the first stage are marked $\boldsymbol{\Delta}$ and of the second stage $\bullet$, the line is the guide for the eye. 
Table 1. The obtained kinetic parameters of the first stage of the release.

\begin{tabular}{|c|c|c|c|c|c|c|}
\hline $\begin{array}{l}\text { Kinetic } \\
\text { Model }\end{array}$ & $\begin{array}{c}\text { Kinetic } \\
\text { Parameters }\end{array}$ & F6 & F7 & F8 & F9 & F10 \\
\hline \multirow{3}{*}{$\mathrm{F}-\mathrm{O}$} & $\begin{array}{l}\mathrm{k}_{1} \times 10^{3} \\
{\left[\mathrm{~min}^{-1}\right]}\end{array}$ & $7.8 \pm 1.9$ & $8.3 \pm 1.3$ & $8.2 \pm 0.2$ & $7.2 \pm 1.5$ & $9.6 \pm 2.7$ \\
\hline & $\mathrm{R}^{2}$ & $0.87 \pm 0.08$ & $0.95 \pm 0.05$ & $0.88 \pm 0.04$ & $0.9 \pm 0.1$ & $0.85 \pm 0.1$ \\
\hline & $\begin{array}{c}\mathrm{t}_{0.5} \\
{[\mathrm{~min}]}\end{array}$ & $101 \pm 29$ & $84 \pm 13$ & $88 \pm 23$ & $98.9 \pm 24.6$ & $73.3 \pm 21.5$ \\
\hline \multirow[t]{3}{*}{$\mathrm{S}-\mathrm{O}$} & $\begin{array}{c}\mathrm{k}_{2} \times 10^{5} \\
{\left[\mathrm{mg}^{-1}\right.} \\
\left.\min ^{-1}\right]\end{array}$ & $3.3 \pm 0.6$ & $3.3 \pm 0.4$ & $3.9 \pm 1.0$ & $3.4 \pm 0.6$ & $4.6 \pm 1.1$ \\
\hline & $R^{2}$ & $0.93 \pm 0.09$ & $0.97 \pm 0.04$ & $0.90 \pm 0.06$ & $0.9 \pm 0.1$ & $0.86 \pm 0.12$ \\
\hline & $\begin{array}{c}\mathrm{t}_{0.5} \\
{[\mathrm{~min}]}\end{array}$ & $89 \pm 18$ & $84 \pm 10$ & $63 \pm 14$ & $83.6 \pm 21.3$ & $60.8 \pm 17.1$ \\
\hline \multirow[t]{3}{*}{$\mathrm{H}$} & $\begin{array}{c}\mathrm{k}_{\mathrm{H}} \\
{[\mathrm{mg} \times} \\
\left.\min ^{-1 / 2}\right]\end{array}$ & $24.9 \pm 1.9$ & $21.3 \pm 1.2$ & $30.3 \pm 2.6$ & $27.5 \pm 2.6$ & $31.0 \pm 2.7$ \\
\hline & $R^{2}$ & $0.7 \pm 0.2$ & $0.93 \pm 0.09$ & $0.72 \pm 0.20$ & $0.66 \pm 0.19$ & $0.69 \pm 0.19$ \\
\hline & $\begin{array}{c}\mathrm{t}_{0.5} \\
{[\mathrm{~min}]}\end{array}$ & $64.7 \pm 9.7$ & $77.7 \pm 8.4$ & $42.8 \pm 7.5$ & $46.7 \pm 8.7$ & $39.4 \pm 7.1$ \\
\hline \multirow{4}{*}{$\mathrm{K}-\mathrm{P}$} & $\begin{array}{l}\mathrm{k}_{\mathrm{K}-\mathrm{P}} \times 10^{2} \\
{\left[\mathrm{~min}^{-\mathrm{n}}\right]}\end{array}$ & $9.7 \pm 2.4$ & $4.8 \pm 1.5$ & $20.3 \pm 4.3$ & $20.8 \pm 5.4$ & $14.4 \pm 7.2$ \\
\hline & $\mathrm{n}$ & $0.50 \pm 0.07$ & $0.65 \pm 0.08$ & $0.35 \pm 0.06$ & $0.30 \pm 0.07$ & $0.42 \pm 0.12$ \\
\hline & $\mathrm{R}^{2}$ & $0.96 \pm 0.09$ & $0.96 \pm 0.08$ & $0.94 \pm 0.04$ & $0.90 \pm 0.07$ & $0.85 \pm 0.13$ \\
\hline & $\begin{array}{c}\mathrm{t}_{0.5} \\
{[\mathrm{~min}]}\end{array}$ & $30 \pm 17$ & $37 \pm 19$ & $15 \pm 7$ & $18 \pm 15$ & $21.2 \pm 25.5$ \\
\hline \multirow{3}{*}{$\mathrm{H}-\mathrm{C}$} & $\begin{array}{c}\mathrm{k}_{\mathrm{H}-\mathrm{C}} \times 10^{2} \\
{\left[\mathrm{mg}^{1 / 3} \min ^{-1}\right]}\end{array}$ & $1.6 \pm 0.4$ & $1.8 \pm 0.3$ & $1.6 \pm 0.5$ & $1.4 \pm 0.3$ & $1.9 \pm 0.6$ \\
\hline & $R^{2}$ & $0.86 \pm 0.08$ & $0.94 \pm 0.05$ & $0.87 \pm 0.04$ & $0.88 \pm 0.12$ & $0.84 \pm 0.11$ \\
\hline & $\begin{array}{c}\mathrm{t}_{0.5} \\
{[\mathrm{~min}]}\end{array}$ & $104 \pm 31$ & $85.0 \pm 14.7$ & $94.7 \pm 26.3$ & $\begin{array}{c}105.7 \pm \\
28.0\end{array}$ & $79.9 \pm 24.6$ \\
\hline \multicolumn{2}{|c|}{ Best fit } & K-P & $\mathrm{S}-\mathrm{O}$ & K-P & $\begin{array}{l}\text { F-O, S-O, } \\
\text { K-P }\end{array}$ & $\mathrm{S}-\mathrm{O}$ \\
\hline
\end{tabular}

F-O-first order, S-O-second order, H-Higuchi model, K-P-Korsmeyer-Peppas model, H-C-Hixon-Crowell model.

Table 2. The obtained kinetic parameters of the second stage of the release.

\begin{tabular}{|c|c|c|c|c|c|c|}
\hline $\begin{array}{l}\text { Kinetic } \\
\text { Model }\end{array}$ & $\begin{array}{c}\text { Kinetic } \\
\text { Parameters }\end{array}$ & F6 & F7 & F8 & F9 & F10 \\
\hline \multirow{3}{*}{$\mathrm{Z}-\mathrm{O}$} & $\begin{array}{c}\mathrm{k}_{0} \times 10 \\
{\left[\mathrm{mg} \mathrm{min}^{-1}\right]}\end{array}$ & $2.4 \pm 0.4$ & $1.7 \pm 0.5$ & $1.6 \pm 0.4$ & $1.4 \pm 0.4$ & $1.8 \pm 0.6$ \\
\hline & $R^{2}$ & $0.89 \pm 0.04$ & $0.72 \pm 0.20$ & $0.74 \pm 0.25$ & $0.77 \pm 0.13$ & $0.64 \pm 0.32$ \\
\hline & $\begin{array}{c}\mathrm{t}_{0.5} \\
{[\mathrm{~min}]}\end{array}$ & $383.5 \pm 60.3$ & $541.6 \pm 182.5$ & $836.4 \pm 355.7$ & $816.6 \pm 230.7$ & $1061.4 \pm 1091.6$ \\
\hline \multirow{3}{*}{$\mathrm{F}-\mathrm{O}$} & $\begin{array}{l}\mathrm{k}_{1} \times 10^{3} \\
{\left[\mathrm{~min}^{-1}\right]}\end{array}$ & $1.7 \pm 0.3$ & $1.1 \pm 0.3$ & $1.2 \pm 0.3$ & $1.1 \pm 0.3$ & $1.6 \pm 0.5$ \\
\hline & $\mathrm{R}^{2}$ & $0.88 \pm 0.05$ & $0.71 \pm 0.20$ & $0.73 \pm 0.26$ & $0.76 \pm 0.15$ & $0.65 \pm 0.35$ \\
\hline & $\begin{array}{c}\mathrm{t}_{0.5} \\
{[\mathrm{~min}]}\end{array}$ & $451.5 \pm 75.1$ & $675.9 \pm 238.0$ & $705.7 \pm 327.7$ & $677.6 \pm 184.1$ & $724.3 \pm 961.6$ \\
\hline \multirow{3}{*}{$\mathrm{S}-\mathrm{O}$} & $\begin{array}{c}\mathrm{k}_{2} \times 10^{5} \\
{\left[\mathrm{mg}^{-1} \mathrm{~min}^{-1}\right]}\end{array}$ & $1.2 \pm 0.2$ & $0.73 \pm 0.27$ & $1.0 \pm 0.3$ & $0.9 \pm 0.3$ & $1.4 \pm 0.4$ \\
\hline & $\mathrm{R}^{2}$ & $0.87 \pm 0.06$ & $0.59 \pm 0.21$ & $0.58 \pm 0.3$ & $0.67 \pm 0.18$ & $0.74 \pm 0.36$ \\
\hline & $\begin{array}{c}\mathrm{t}_{0.5} \\
{[\mathrm{~min}]}\end{array}$ & $413.0 \pm 69.0$ & $742.1 \pm 358.9$ & $\begin{array}{c}1005.1 \pm \\
641.4\end{array}$ & $716.5 \pm 240.9$ & $381.8 \pm 130.5$ \\
\hline
\end{tabular}


Table 2. Cont.

\begin{tabular}{|c|c|c|c|c|c|c|}
\hline $\begin{array}{l}\text { Kinetic } \\
\text { Model }\end{array}$ & $\begin{array}{c}\text { Kinetic } \\
\text { Parameters }\end{array}$ & F6 & F7 & F8 & F9 & F10 \\
\hline \multirow{3}{*}{$\mathrm{H}$} & $\begin{array}{c}\mathrm{k}_{\mathrm{H}} \\
{\left[\mathrm{mg} \times \mathrm{min}^{-1 / 2}\right]}\end{array}$ & $7.5 \pm 1.3$ & $5.2 \pm 1.6$ & $5.1 \pm 1.1$ & $4.4 \pm 1.0$ & $5.8 \pm 1.7$ \\
\hline & $R^{2}$ & $0.89 \pm 0.04$ & $0.71 \pm 0.19$ & $0.76 \pm 0.24$ & $0.81 \pm 0.12$ & $0.66 \pm 0.31$ \\
\hline & $\begin{array}{c}\mathrm{t}_{0.5} \\
{[\mathrm{~min}]}\end{array}$ & $89.5 \pm 27.5$ & $193.8 \pm 146.4$ & $651.0 \pm 694.9$ & $477.0 \pm 247.0$ & $1505.5 \pm 3641.3$ \\
\hline \multirow{3}{*}{$\mathrm{H}-\mathrm{C}$} & 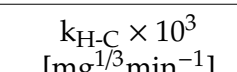 & $2.9 \pm 0.5$ & $1.9 \pm 0.6$ & $2.1 \pm 0.5$ & $1.8 \pm 0.5$ & $2.5 \pm 0.8$ \\
\hline & $\mathrm{R}^{2}$ & $0.89 \pm 0.04$ & $0.71 \pm 0.20$ & $0.73 \pm 0.26$ & $0.77 \pm 0.14$ & $0.65 \pm 0.34$ \\
\hline & $\begin{array}{c}\mathrm{t}_{0.5} \\
{[\mathrm{~min}]}\end{array}$ & $440.1 \pm 71.3$ & $648.3 \pm 223.9$ & $673.7 \pm 303.2$ & $651.0 \pm 175.4$ & $674.6 \pm 781.9$ \\
\hline & Best fit & $\mathrm{Z}-\mathrm{O}, \mathrm{H}, \mathrm{H}-\mathrm{C}$ & $\mathrm{Z}-\mathrm{O}$ & $\mathrm{H}$ & $\mathrm{H}$ & S-O \\
\hline
\end{tabular}

\subsection{The Difference Factor $f_{1}$, the Similarity Factor $f_{2}$}

The influence of the incorporation of a synthetic polymer into the beads on the release behaviour of 5-ASA was evaluated using the difference factor $f_{1}$ and the similarity factor $f_{2}$. The calculated values of $\mathrm{f}_{1}$ and $\mathrm{f}_{2}$ are listed in Table 3 .

Table 3. The values of the difference factor $f_{1}$ and the similarity factor $f_{2}$ obtained by comparing the release profile of 5-ASA from formulations F6-F10.

\begin{tabular}{ccccccc}
\hline Factors of Difference and Similarity & \multicolumn{2}{c}{ Formulations } & F7 & F8 & F9 & F10 \\
\hline & & F6 & 7.26 & 19.92 & 12.15 & 19.59 \\
\cline { 2 - 6 }$f_{1}$ & F7 & - & 21.27 & 19.64 & 27.70 \\
\cline { 2 - 6 } & & F8 & - & - & 2.70 & 6.22 \\
\cline { 2 - 6 } & & F9 & - & - & - & 7.45 \\
\hline & $f_{2}$ & F6 & 66.49 & 48.53 & 57.34 & 48.99 \\
\cline { 2 - 6 } & & F7 & - & 48.53 & 50.11 & 43.38 \\
\cline { 2 - 6 } & & F8 & - & - & 81.30 & 69.64 \\
\hline
\end{tabular}

According to FDA recommendations [25], $\mathrm{f}_{1}$ values ranging from $0-15$ and $\mathrm{f}_{2}$ values greater than 50 ensure the similarity or equivalence of two release curves. It was found that the incorporation of PVP or PEG 4000 into the pectin beads changed the release behavior of 5-ASA from the beads. The $f_{1}$ values were higher than 15 , and the $f_{2}$ values were below 50 , indicating the difference. The results were consistent with the kinetic analysis, which also revealed that the incorporation of a synthetic polymer in the pectin beads may prolong the release of 5-ASA. However, the incorporation of PA and AX into the pectin beads did not significantly influence the release behavior of the drug. The obtained values of $\mathrm{f}_{1}$ were below 15 , and the values of $\mathrm{f}_{2}$ were above 50 , suggesting that the dissolution process was similar.

A comparison of the release of 5-ASA from F7 containing PA with the release from F8, F9 and F10 revealed differences in the release behavior. The obtained $f_{1}$ values were not in the range $0-15$, with values of $27.27,19.64$, and 27.70 , respectively. In the comparison of the drug release from F7 and F8 as well as that from F7 and F10, the variability in $\mathrm{f}_{2}$ was confirmed. In the comparison of the calculated $\mathrm{f}_{2}$ for the release of 5-ASA from F7 and F9, no difference was observed, although $\mathrm{f}_{2}$ was slightly above 50, with a value of 50.11. However, it is known that the similarity is higher for 
values closer to 100 [20]. Thus, it can be concluded that the release behavior of 5-ASA from the studied formulations was also dependent on the type of the synthetic polymer incorporated in the formulation.

\subsection{Statistical Analysis}

The influence of the variability of formulations on the release of 5-ASA was studied by employing one-way analysis of variance (ANOVA). This test combined with Tukey's honest significant difference test (Tukey's HSD test) can be used when the impact of one factor on the results of the conducted research is analyzed [26]. The data obtained in the present work are summarized in Table 4.

Table 4. The values of Tukey's HSD test.

\begin{tabular}{ccccc}
\hline Formulations & F7 & F8 & F9 & F10 \\
\hline F6 & 3.25 & 6.94 & 6.15 & 10.01 \\
\hline F7 & - & 10.18 & 9.40 & 13.26 \\
\hline F8 & - & - & 0.78 & 3.08 \\
\hline F9 & - & - & - & 3.86 \\
\hline
\end{tabular}

The only difference was noticed in the comparison of the dissolution profiles of the drug from formulations F7 and F10. Both formulations contained the synthetic polymer PA or PEG 4000, indicating that the synthetic polymer type influenced the drug release. The same difference was observed from the analysis of the $\mathrm{f}_{1}$ and $\mathrm{f}_{2}$ factors. However, in the comparison of the different formulations, both factors indicated a difference in the drug release that was not found using ANOVA. It is worth noting that ANOVA was not mentioned in any of the FDA documents, although this method was considered useful in previous studies [20,22,26],. The use of ANOVA improves knowledge of the dissolution process of controlled-release formulations.

\subsection{FTIR Spectroscopy}

To evaluate the interactions between the drug and the natural polymer as well as the interactions between the drug and the synthetic polymer, the FTIR spectra of the pure components and formulations F1-F10 as well as their physical mixtures were recorded. The most interesting spectra are shown in Figure 6. The measured FTIR spectra of 5-ASA showed a broad absorption band at $2773 \mathrm{~cm}^{-1}$ attributed to the stretching vibration of the $\mathrm{OH}$ group. According to Mladenovska et al. [27] and $\mathrm{Hu}$ et al. [28], the characteristic bands at $1650 \mathrm{~cm}^{-1}$ belonging to the $\mathrm{C}=\mathrm{O}$ group, $1620 \mathrm{~cm}^{-1}$ assigned to the $\mathrm{N}-\mathrm{H}$ group and $1356 \mathrm{~cm}^{-1}$ corresponding to $\mathrm{C}-\mathrm{N}$ stretching were observed. The characteristic bands of 5-ASA at 1494, 1454, 774, 538, and $485 \mathrm{~cm}^{-1}$ were also observed. All maxima were found in the spectra of formulations F6-F10 as well as in the spectra of their corresponding physical mixtures. These results suggest the absence of an interaction between the drug and the polymers. Neufeld et al. [13] also reported that there was no interaction between 5-ASA and pectin in their physical mixture. 


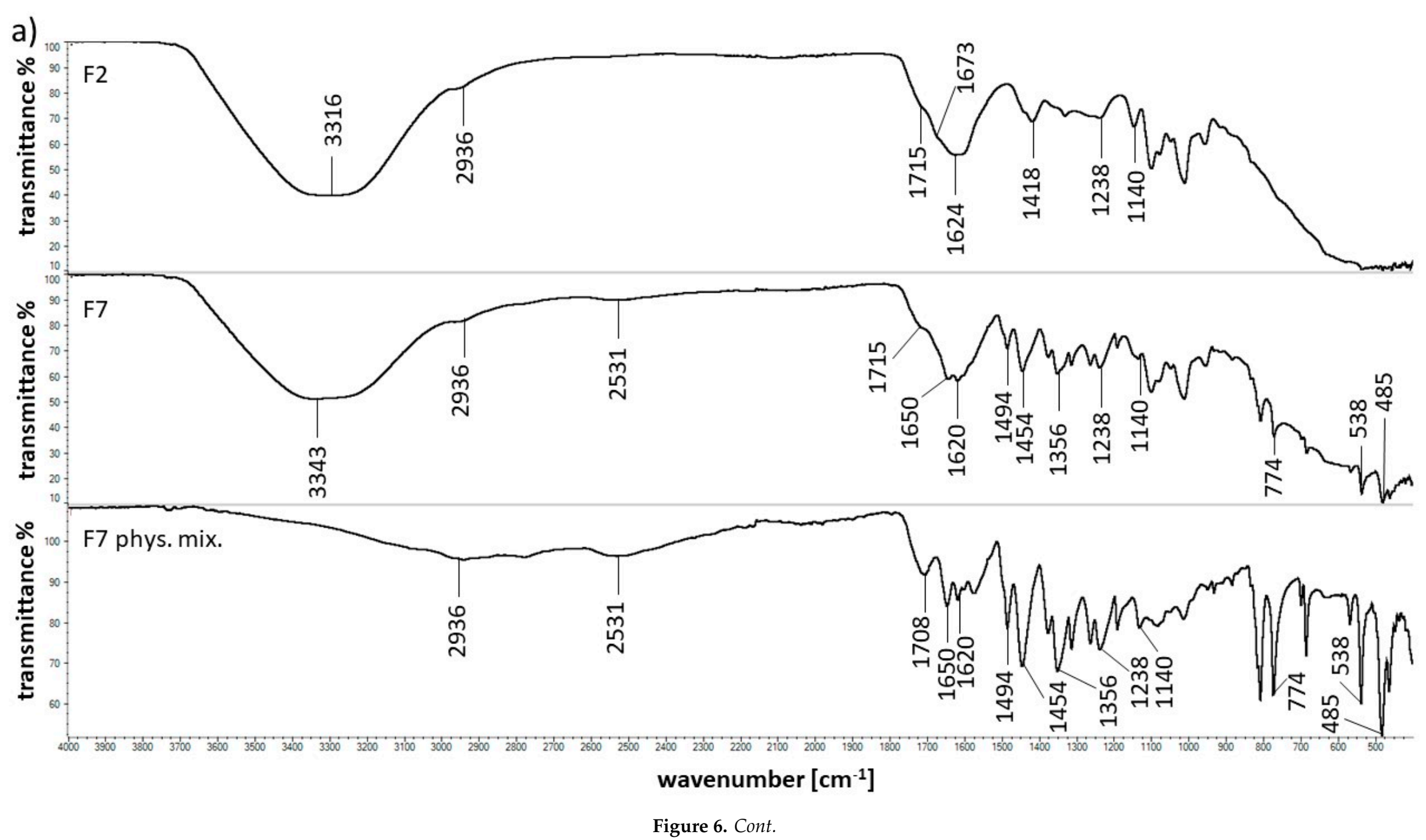




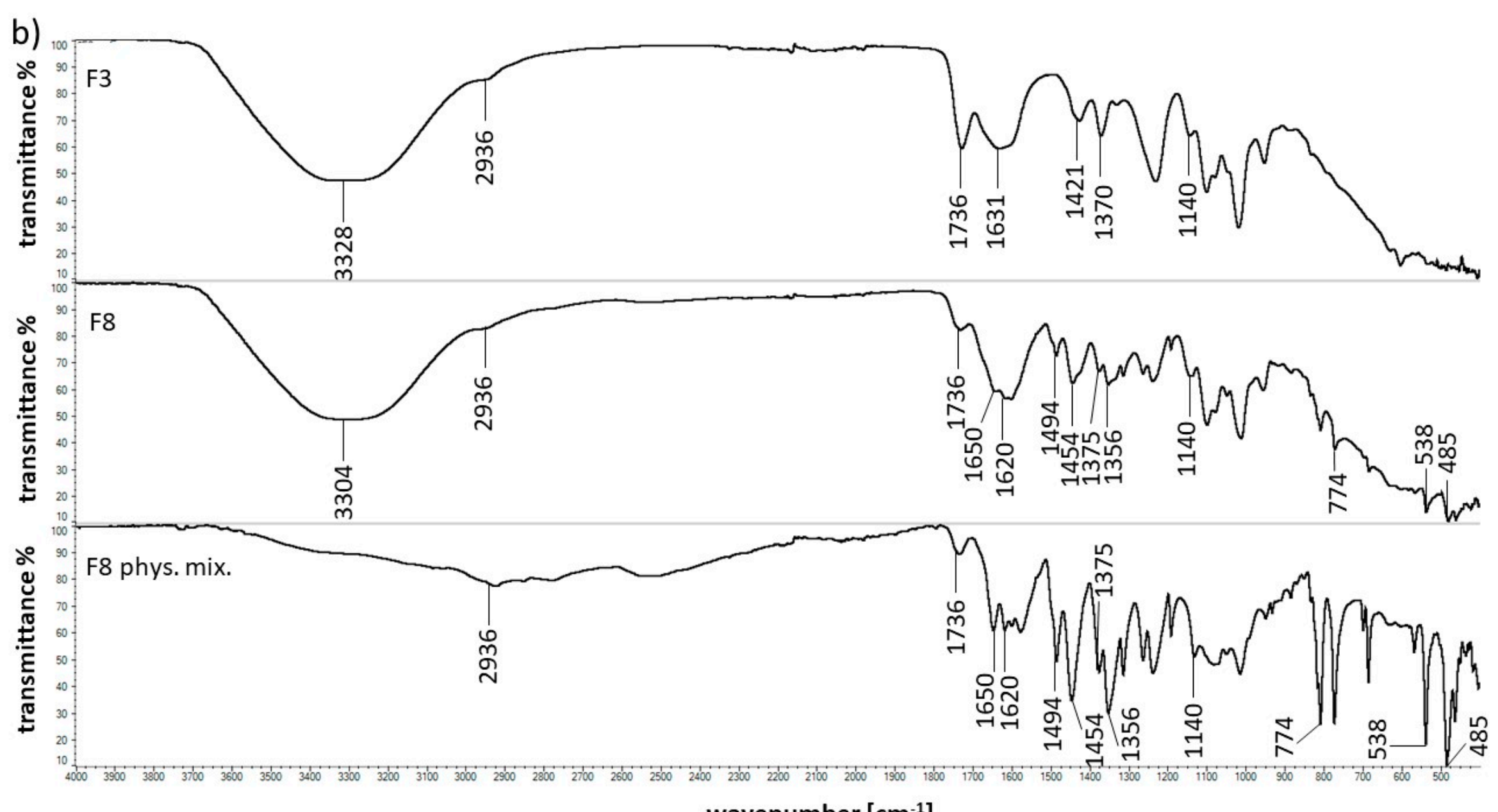

Figure 6. Cont. 


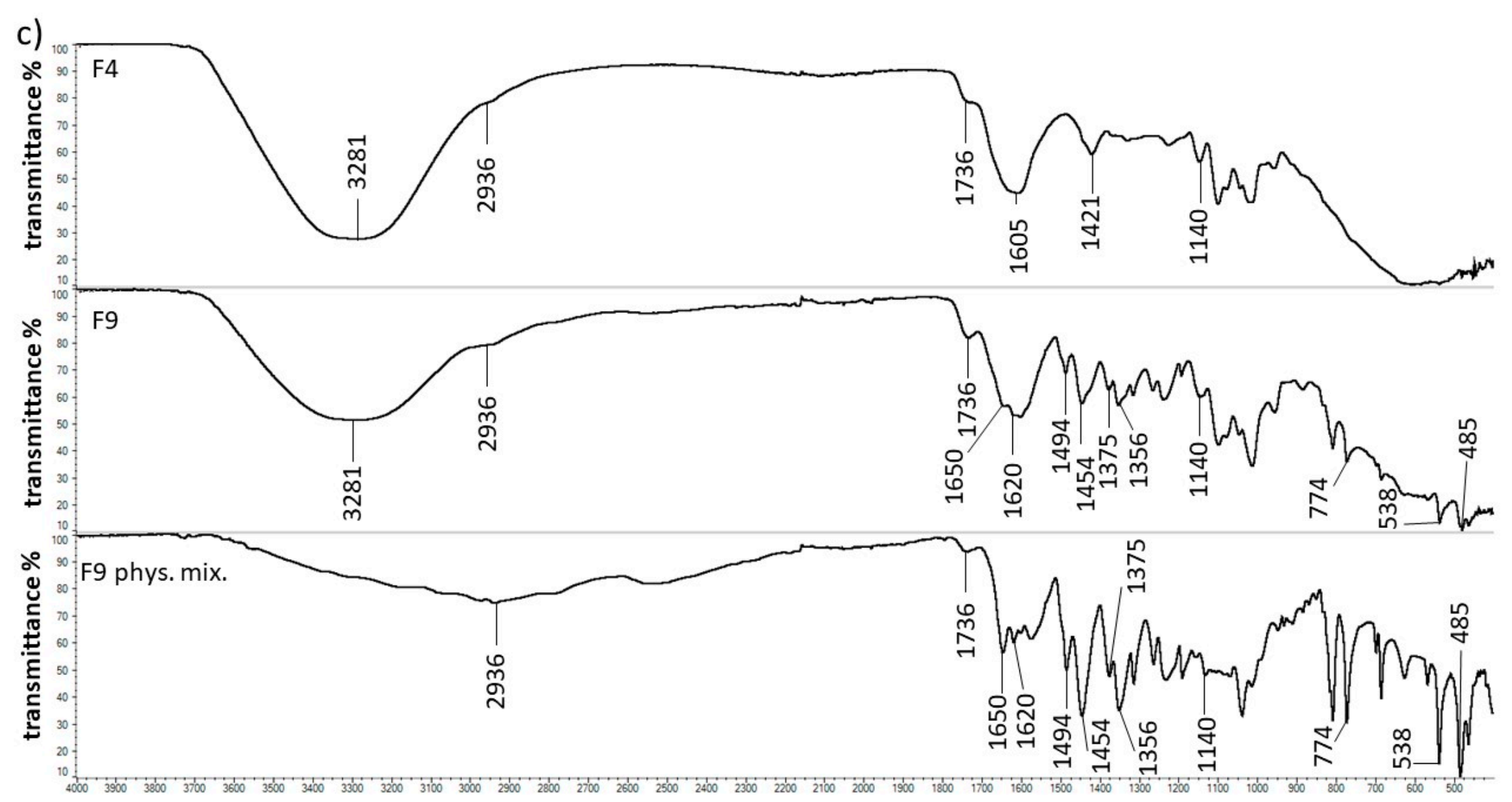
wavenumber $\left[\mathrm{cm}^{-1}\right]$

Figure 6. Cont. 


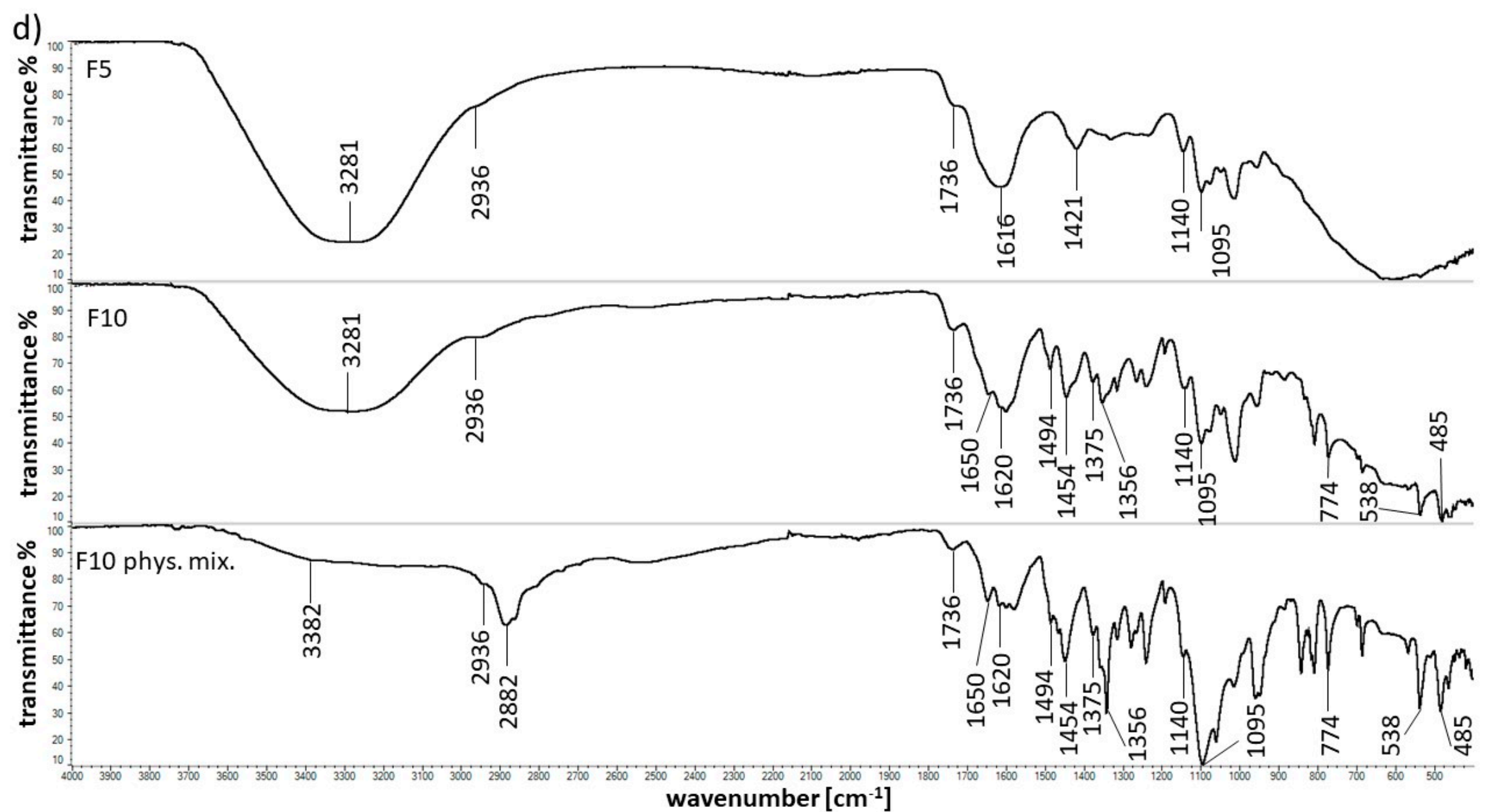

Figure 6. The FTIR spectra of the formulation of (a) F2, F7 and its physical mixture; (b) F3, F8 and its physical mixture (c) F4, F9 and its physical mixture; (d) F5, F10 and its physical mixture. 
The characteristic APN bands were described in our previous work and were located at 2936, $1736,1673,1596,1421$, and $1140 \mathrm{~cm}^{-1}$ [29]. The bands at 2936, 1736, and $1140 \mathrm{~cm}^{-1}$ were found in the spectra of formulations F1-F10 and their physical mixtures, although in the spectra of F2, F7 and its physical mixture, the maximum at $1736 \mathrm{~cm}^{-1}$ associated with the $\mathrm{C}=\mathrm{O}$ stretching vibration of the ester was shifted to $1715 \mathrm{~cm}^{-1}$. Moreover, in the spectrum of formulation F2 in Figure $6 \mathrm{a}$, a band at $1624 \mathrm{~cm}^{-1}$ appeared, and simultaneously, the intensive band at $1697 \mathrm{~cm}^{-1}$ assigned to the PA carboxyl group was not present. This observation was similar to results in our previous work [29] and the study of Alvarez-Gayosso et al. [30]. The vibrations at approximately $1700 \mathrm{~cm}^{-1}$ belonging to the - $\mathrm{COOH}$ group could decrease in intensity upon the appearance of the maximum in the range of 1650 to $1500 \mathrm{~cm}^{-1}$ attributed to $\mathrm{COO}^{-}$stretching. This observation suggests that there was an interaction between the APN carboxylate group and PA carboxyl group. The possibility of this interaction was confirmed by the disappearance of the PA band at $1451 \mathrm{~cm}^{-1}$ and a shift in the PA maximum at $1227 \mathrm{~cm}^{-1}$ to $1238 \mathrm{~cm}^{-1}$ in the spectra of F2, F7 and its physical mixture. The interaction between pectin and another polymer, brea gum, was studied by Slavutsky et al. [31]. It was observed that the band of the - $\mathrm{OH}$ group and asymmetric $\mathrm{COO}^{-}$stretching vibrations were shifted to lower frequencies, indicating the formation of hydrogen bonds between both polymers. A similar interaction was also found between pectin and sodium alginate [32]. The observed interaction between APN and PA may be responsible for the discrepancy in the dissolution study from F7 and F10 obtained from ANOVA test. It was mentioned that the comparison of the release of 5-ASA from formulations doped with synthetic polymers indicated the differences between F7 and F10. However, comparing the release from $\mathrm{F} 6$ and $\mathrm{F} 7$ based on $\mathrm{f}_{1}$ and $\mathrm{f}_{2}$ values, no variability was noticed.

Carboxyl-carboxylate proton binding was also observed in previous studies [33-36]. The existence of hydrogen bonds between two carboxyl groups $\mathrm{O}-\mathrm{H} \cdots \mathrm{O}$ was found. The band of PA at $1412 \mathrm{~cm}^{-1}$ was shifted to $1418 \mathrm{~cm}^{-1}$ in the spectrum of F2. However, in the spectra of F7 and its physical mixture, the peak at $1412 \mathrm{~cm}^{-1}$ was not visible. This may indicate an interaction between PA and 5-ASA because 5-ASA was absent in formulation F2. In addition, the interaction between the carboxyl group of PA and the carboxyl group of the drug-salicylic acid was proposed in our previous work [29]. Since 5-ASA is the amine derivative of salicylic acid, a similar effect is also possible in the case of 5-ASA and PA.

The APN peak at $1673 \mathrm{~cm}^{-1}$ was very weak in the spectra of formulations F1 and F2 and was not found in the spectra of F3-F10 and their corresponding physical mixtures. The analysis of the spectra of F1-F5 revealed that the APN maximum at $1596 \mathrm{~cm}^{-1}$ was shifted to 1600, 1624, 1631, 1605 and $1616 \mathrm{~cm}^{-1}$ and was not present in the spectra of formulations F6-F10 and their physical mixtures. These observations may be due to an interaction between APN carboxyl groups and calcium ions. The peaks in the FTIR spectrum of calcium chloride observed at 1628 and $1613 \mathrm{~cm}^{-1}$ disappeared in the spectra of formulations F1-F10 and their physical mixtures, confirming the interaction of the APN carboxyl group with calcium ions.

The FTIR spectrum of PVP was discussed in previous investigations [37,38]. It is interesting to note that the characteristic band at $1661 \mathrm{~cm}^{-1}$ assigned to the $\mathrm{C}=\mathrm{O}$ stretching vibration was not present in the spectra of F3, F8 and the physical mixture of F8 (Figure 6b). It should be mentioned that in the spectrum of F3, the wide band at $1631 \mathrm{~cm}^{-1}$ was observed and was difficult to explicitly assign to any of the F3 components. According to the investigation of Alvarez-Gayosso et al. [30], vibration bands assigned to carboxylic acid, $-\mathrm{COOH}$, appear at approximately $1700 \mathrm{~cm}^{-1}$, although the carboxylate ion $-\mathrm{COO}^{-}$vibrations are located in the range from 1650 to $1500 \mathrm{~cm}^{-1}$. This observation indicates an interaction between the PVP carbonyl group and APN carboxylate group. Additionally, the PVP neighboring peaks at 1496 and $1463 \mathrm{~cm}^{-1}$ were not observed in the spectra of F3, F8 and the physical mixture of F8. These results may confirm the interaction between both polymers. Wu et al. [39] found an interaction between the hydroxyl group on the carboxyl of PA $(-\mathrm{COOH})$ and the oxygen lone pair of the carbonyl group of PVP $(\mathrm{C}=\mathrm{O})$.

Moreover, it was noticed that the PVP bands located at 1425 and $1370 \mathrm{~cm}^{-1}$ were not found in the spectra of F8 and its physical mixture, suggesting an interaction between PVP and 5-ASA because 
the maxima were present in the spectrum of formulation F3, into which no 5-ASA was incorporated. This FTIR data were consistent with the results obtained from release study. The parameter $f_{1}$ and $\mathrm{f}_{2}$ indicated the difference in the dissolution of 5-ASA from F6 and F8. In the F6 formulation, no interaction between APN and 5-ASA was observed, but in F8 the interaction between the doped polymer and the drug was noticed.

The FTIR spectra of formulations F4 and F9 containing AX were illustrated in Figure 6c. The analysis revealed that the characteristic maxima of $\mathrm{AX}$ at 1640,1544,1440,1388, and $1176 \mathrm{~cm}^{-1}$ were not found in the spectra of F4, F9 and its physical mixture. The $-\mathrm{C}=\mathrm{O}$ group exists in the structure of $\mathrm{AX}$, as in the case of PA and PVP. The carbonyl groups of AX may bind to the carboxyl groups of APN or 5-ASA. This observation is consistent with the results obtained from the FTIR results of F3 and F8 formulations containing PVP.

The obtained FTIR spectrum of PEG 4000 has characteristic bands at the frequencies of 3447, 2882, and $1095 \mathrm{~cm}^{-1}$, which is in agreement with previous investigations [40,41]. All the maxima were also found in the spectrum of the physical mixture of F10 shown in Figure 6d. However, the weak band at $3447 \mathrm{~cm}^{-1}$ was shifted to $3382 \mathrm{~cm}^{-1}$ in the spectrum of the physical mixture of F10. In the case of the spectra of formulations F5 and F10 (Figure 6d), the maxima at 3447 and $2882 \mathrm{~cm}^{-1}$ were not found. This may be explained by an interaction of the terminal -OH group belonging to PEG 4000 with hydroxyl group belonging to APN. This observation may also be due to the presence of water molecules in formulations F5 and F10, which has a broad band assigned to the OH group. The hydrogen from one molecule may bind the oxygen from the other moiety and form the hydrogen bond. The signal at $1095 \mathrm{~cm}^{-1}$ observed in the spectra of formulations F5, F10 and the physical mixture of F10 may be assigned to the interior -C-O-C- ether group of PEG [42]. The hydrogen bond may explain the difference in the release pattern of 5-ASA from F10 in comparison to the release from F6.

It is worth mentioning that the FTIR spectra of all studied formulations showed a broad band in the range of $3000-3600 \mathrm{~cm}^{-1}$ related to the existence of free or bound $\mathrm{OH}$ groups.

To conclude, the FTIR study revealed possible interactions between pectin and the synthetic polymers as well as the polymer and the drug. These results may explain the variability in the drug release from formulations F6-F10 containing different synthetic polymers.

\subsection{DSC Study}

The thermograms of formulations containing synthetic polymer, as well as their physical mixtures are shown in Figure 7, and the temperatures of obtained maxima are collected in Table 5. The results allowed us to study the interaction between the formulations components. The measured DSC curve of pure 5-ASA revealed a sharp endothermic peak at $284.1^{\circ} \mathrm{C}$ related to its melting point. This value was slightly higher comparing to the literature values of 270.0 and $277.5^{\circ} \mathrm{C}$ obtained by Neufeld et al. [13] and $\mathrm{Hu}$ et al. [28], respectively. The peak of 5-ASA was found in the DSC thermograms of formulations F7-F10 containing the drug as well as on their physical mixtures and were presented in Figure 7. The maximum on the curves of physical mixtures was in the range $270.1-278.4^{\circ} \mathrm{C}$ and corresponded to the literature data $[13,28]$, and was slightly shifted to lower temperatures $259.2-263.5^{\circ} \mathrm{C}$ in the case of formulations F7-F10. These results indicate no interaction between the drug and polymers.

The two endothermic events of $\mathrm{CaCl}_{2}$ obtained at 116.9 and $138.7^{\circ} \mathrm{C}$ were not found in the thermograms of formulations F1-F10. Furthermore, the two maxima of $\mathrm{CaCl}_{2}$ did not exist in the thermograms of their physical mixtures.

The obtained APN thermogram was similar to the thermograms shown in our previous study [29]. The thermal profile of APN revealed an endotherm at $73.0^{\circ} \mathrm{C}$ assigned to the evaporation of water and two endothermic peaks at 178.9 and $192.8^{\circ} \mathrm{C}$, as well as an exothermic process at $236.2^{\circ} \mathrm{C}$. 


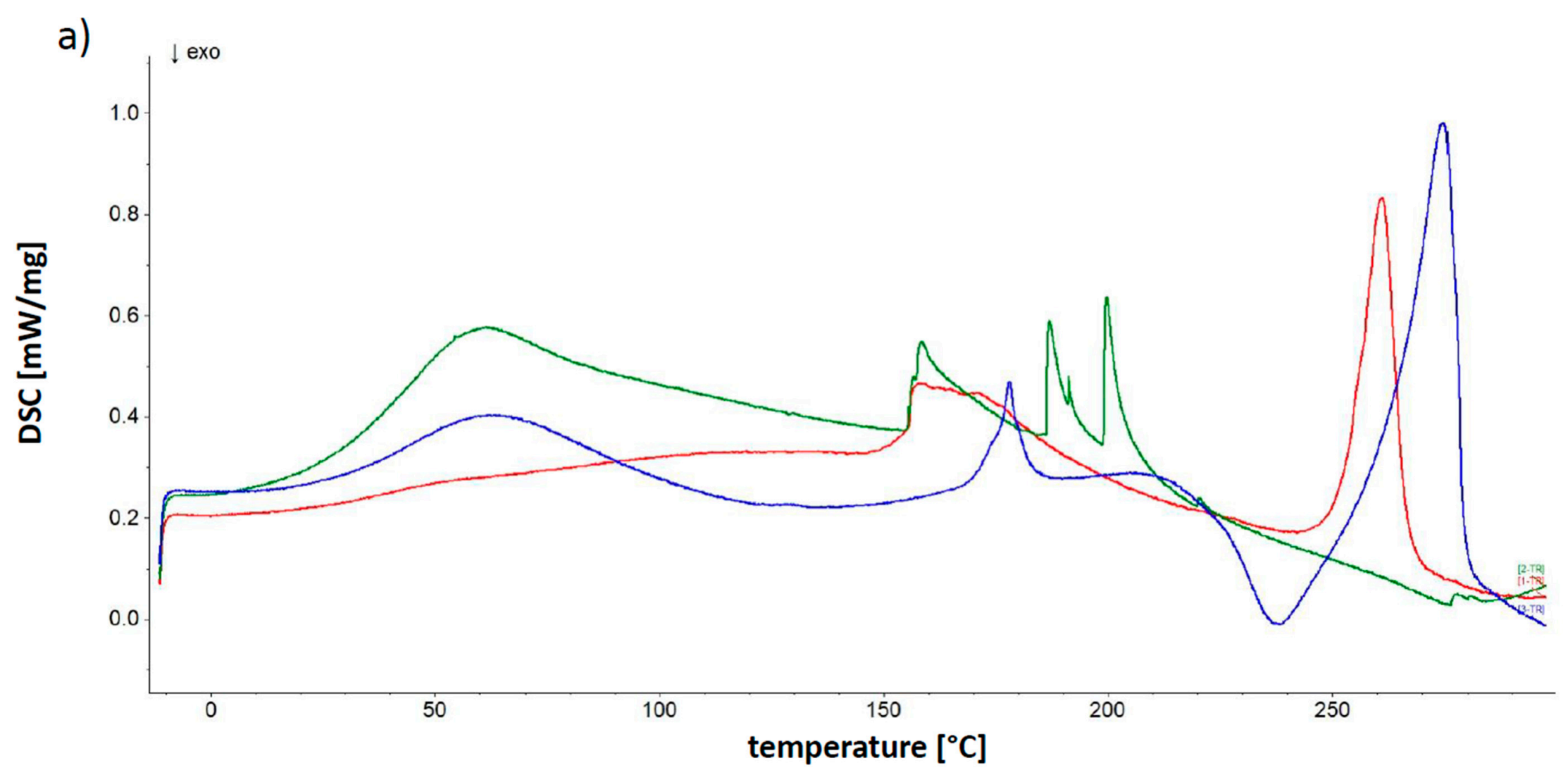

Figure 7. Cont. 


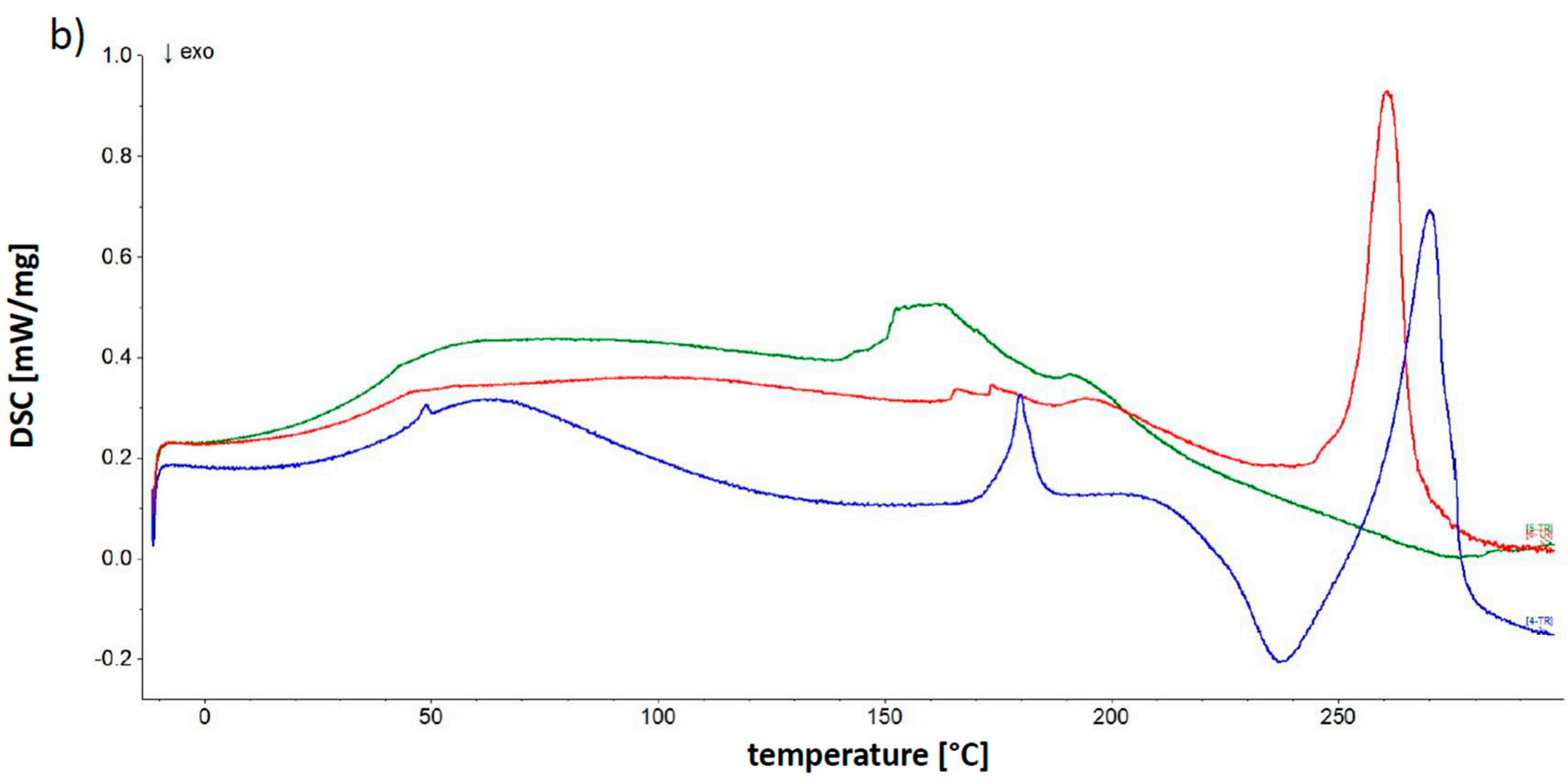

Figure 7. Cont. 


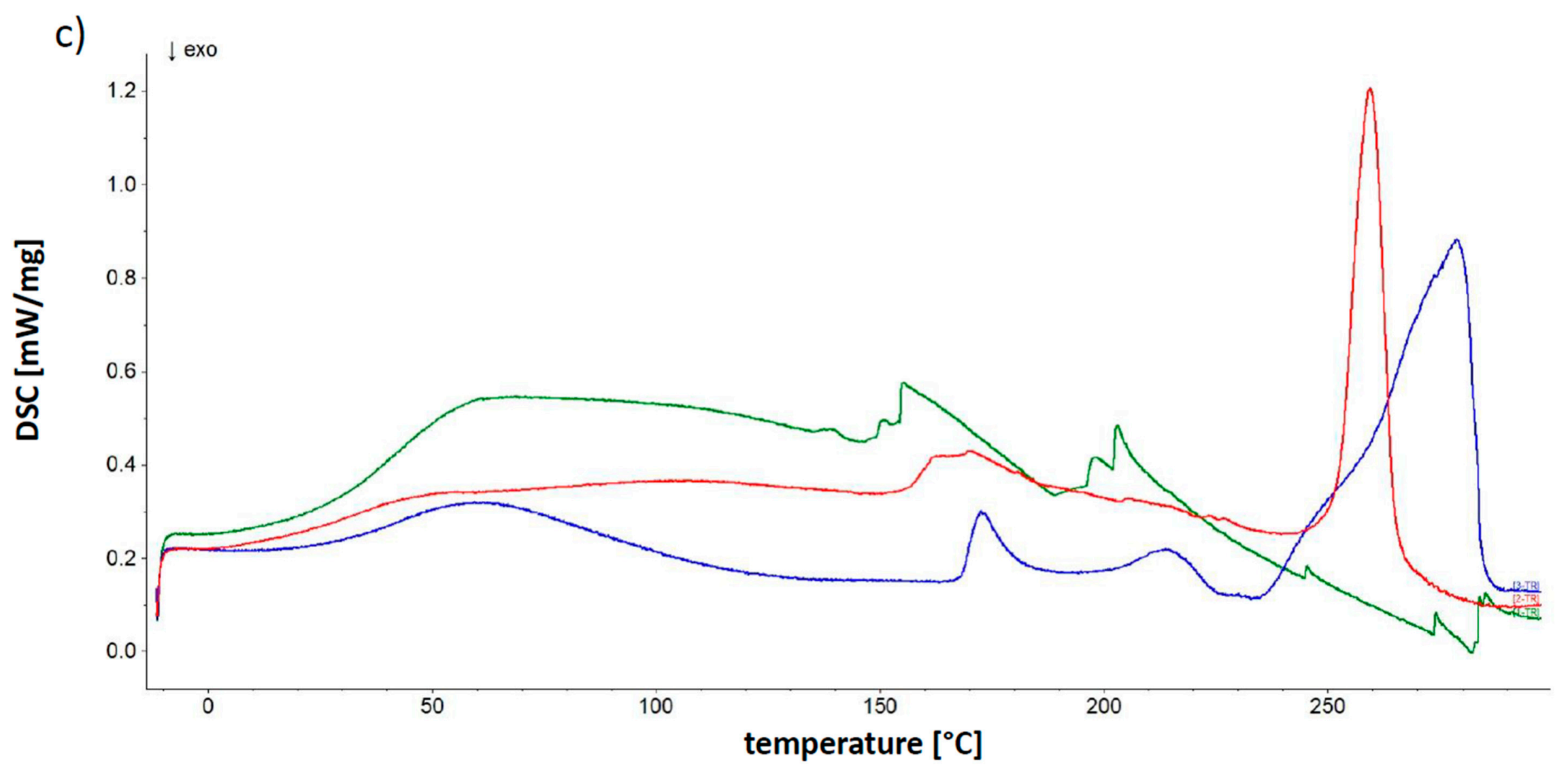

Figure 7. Cont. 


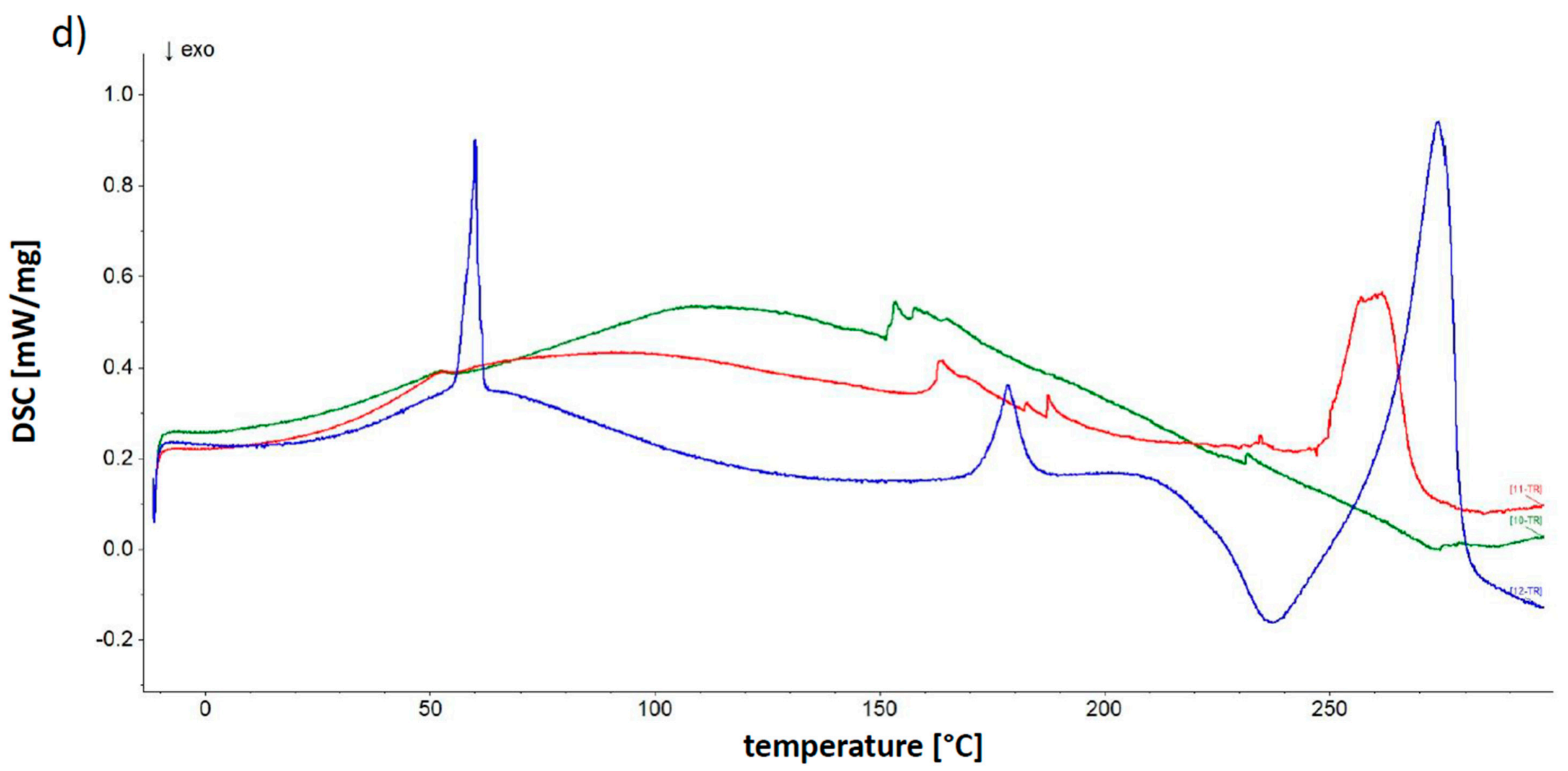

Figure 7. The DSC thermograms of (a) F2 (green line), F7 (red line) and physical mixture of F7 (blue line); (b) F3 (green line), F8 (red line) and physical mixture of F8 (blue line); (c) F4 (green line), F9 (red line) and physical mixture of F9 (blue line); (d) F5 (green line), F10 (red line) and physical mixture of F10 (blue line). 
Table 5. The obtained DSC maxima of formulations F2-F5 and F7-F10 doped with synthetic polymer, and respective physical mixtures $\left(\mathrm{M}_{\mathrm{F} 7}-\mathrm{M}_{\mathrm{F} 10}\right)$, abbreviation described in the text.

\begin{tabular}{cccccccccccc}
\hline F2 & F7 & M F7 & F3 & F8 & MF8 $_{\text {F4 }}$ & F4 & F9 & MF9 & F5 & F10 & MF10 \\
\hline- & 261.2 & 274.7 & - & 260.6 & 270.1 & - & 259.2 & 278.4 & - & 263.5 & 274.2 \\
\hline- & 171.3 & 178.1 & - & 173.7 & 179.9 & - & 169.5 & 172.7 & - & - & 178.5 \\
\hline- & - & 206.2 & 192.0 & 194.4 & 206.4 & 197.8 & - & 213.6 & - & - & 206.8 \\
\hline- & - & $238.4 \downarrow$ & - & - & $238.1 \downarrow$ & - & - & $224.0 \downarrow$ & - & - & $237.5 \downarrow$ \\
\hline 61.1 & - & 62.2 & 49.3 & 46.1 & 48.7 & - & - & - & 52.0 & 52.0 & 60.0 \\
\hline 158.3 & 159.4 & - & $154.4-161.5$ & 166.1 & - & 154.0 & $159.8-169.5$ & - & 152.8 & 162.3 & - \\
\hline 186.3 & - & - & - & - & - & - & - & - & - & 187.4 & - \\
\hline 199.1 & - & - & - & - & - & 202.2 & - & - & - & - & - \\
\hline
\end{tabular}

The APN endotherm at $178.9{ }^{\circ} \mathrm{C}$ was found in the plots of formulations F7-F9 and physical mixtures $\mathrm{M}_{\mathrm{F} 7}-\mathrm{M}_{\mathrm{F} 10}$ in the range $169.5-179.9^{\circ} \mathrm{C}$, although it was not observed in the thermograms of formulations F2-F5 not containing the drug. The weak signal at $192.8{ }^{\circ} \mathrm{C}$ was present in the curves of physical mixtures $\mathrm{M}_{\mathrm{F} 7}-\mathrm{M}_{\mathrm{F} 10}$ between 206.2 and $213.6{ }^{\circ} \mathrm{C}$ and formulations $\mathrm{F} 3, \mathrm{~F} 4, \mathrm{~F} 8$ from 192.0 to $197.8^{\circ} \mathrm{C}$. The exotherm at $234.5^{\circ} \mathrm{C}$ assigned to APN was found in the thermal profiles of physical mixtures $\mathrm{M}_{\mathrm{F} 7}-\mathrm{M}_{\mathrm{F} 10}$ and were located at $224.0-238.4{ }^{\circ} \mathrm{C}$. However, this signal was not found in thermograms of formulations F2-F10.

From the measured thermal profile of PA two endothermic processes were located at 62.4 and $221.5^{\circ} \mathrm{C}$. In Figure 7a both maxima of PA at 62.2 and $206.2^{\circ} \mathrm{C}$ were noticed in the thermogram of the physical mixture of F7. However, the peak at $206.2^{\circ} \mathrm{C}$ may be also assigned to the shifted signal of $\mathrm{APN}$ at $192.8^{\circ} \mathrm{C}$. In the thermogram of F2, the endoderm was noticed at $61.1^{\circ} \mathrm{C}$. Neither the maximum at $62.4^{\circ} \mathrm{C}$ nor the signal at $221.5^{\circ} \mathrm{C}$ was observed in the thermogram of $\mathrm{F} 7$.

The thermograms of F3, F8 doped with PVP, and its physical mixture were presented in Figure 7b. The thermal behavior of PVP revealed an endothermic peak at $47.1^{\circ} \mathrm{C}$ coincided with the reported endothermic process of melting [43]. The signal assigned to PVP was present in all thermograms in Figure $7 \mathrm{~b}$ in the range $46.1-49.3^{\circ} \mathrm{C}$.

In Figure 7c, the thermal profiles of formulations F4, F9 doped with $\mathrm{AX}$ as well as $\mathrm{M}_{\mathrm{F} 9}$ were presented. The obtained AX thermogram showed several broad endothermic events at 57.7, 144.0, 211.3, and $248.8^{\circ} \mathrm{C}$ and exothermic events at approximately $122.1,182.3$, and $266.9^{\circ} \mathrm{C}$. The maxima belonging to $\mathrm{AX}$ were hardly noticeable in the curves in Figure 7c. These results may suggest the interaction between $\mathrm{AX}$ and the components of formulations.

The obtained PEG 4000 thermal profile was similar to the curve from the literature and showed a sharp endothermic maximum at $58.4{ }^{\circ} \mathrm{C}$, and a broad exothermic process at approximately $206.7^{\circ} \mathrm{C}[40,44]$. The thermograms of F5, F10 containing PEG 4000 and physical mixture of F10 were shown in Figure $7 \mathrm{~d}$. The sharp endotherm at about $52.0-60.0^{\circ} \mathrm{C}$ coming from PEG 4000 was observed in all profiles. The exotherm of PEG400 at $206.7^{\circ} \mathrm{C}$ was not observed in Figure $7 \mathrm{~d}$.

Apart from maxima that were assigned to the components of formulations, broad sharp endothermic processes appeared in the range of approximately $152.8-169.5^{\circ} \mathrm{C}$. The new signals were observed in the curves of formulations, although they did not exist in the profiles of physical mixtures. The maxima, together with the absence of signals of $\mathrm{CaCl}_{2}$ as well as the lack of the exotherm of APN may indicate the interaction between calcium ions and APN. Moreover, the disappearance or shifting of APN endotherms, the absence of PA maximum at $221.5^{\circ} \mathrm{C}$ in formulation F2 and F7 and a new peaks at 186.3 and $199.1^{\circ} \mathrm{C}$ in the thermogram of formulation $\mathrm{F} 2$ may be a result of the interaction between the natural and the synthetic polymer. The lack of signals of AX in Figure 7c and the appearance of the new endotherm at $202.2^{\circ} \mathrm{C}$ in the curve of $\mathrm{F} 4$, as well as the absence of the exotherm of PEG400 at $206.7^{\circ} \mathrm{C}$ in Figure $7 \mathrm{~d}$ may be also explained by the bond formation between 
polymers. The DSC study is consistent with the data from the spectroscopic analysis suggesting the interaction between components.

According to Buning et al. [45] numerous preparation proposed in the Crohn's disease have been unrecommended by the medical authorities due to the lack of efficacy or severe side effects. However, 5-ASA is used extensively in considered condition. The presented millibeads may enable achievement of the appropriate 5-ASA concentration in the distal sections of the GIT. The bipolymeric beads are supposed to be protective to the drug, in terms of unfavourable absorption in the stomach.

\section{Materials}

Amidated pectin (APN) was obtained from C\&GSp. z o.o. (Jasło, Poland). $\mathrm{CaCl}_{2}, \mathrm{NaOH}$ and $\mathrm{KH}_{2} \mathrm{PO}_{4}$ were derived from Chempur (Piekary Śląskie, Poland). Polyvinylpyrrolidone (PVP) was obtained from BASF (Ludwigshafen, Germany), polyacrylic acid (PA) was obtained from LUBRIZOL (Wickliffe, OH, USA), and ammonium acryloyldimethyltaurate (AX) was obtained from CLARIANT (Muttenz, Switzerland). Polyethylene glycol (PEG) 4000 was a gift from the local company Hasco-Lek (Wroclaw, Poland). 5-Aminosalicylic acid (5-ASA) was supplied from Sigma-Aldrich (St. Louis, MO, USA). Pectinase was obtained from a local market (activity of 4160 PE/mL, BIOWIN, Łódź, Poland). All synthetic chemicals were of analytical reagent grade and used without further purification.

\section{Methods}

\subsection{Preparation of Pectin Beads}

Pectin beads were prepared using the ionotropic gelation technique [12,14,46]. The composition of formulations F1-F10 was presented in Table 6. The ingredients were dissolved in distilled water. The concentration of APN was 4.5\% (w/v) in formulations F1 and F6. In the other formulations, the APN concentration was $3.6 \%(w / v)$, and the concentration of the synthetic polymer was $1.0 \%(w / v)$. The concentration of 5-ASA in formulations F6-F10 was 2.3\% (w/v). A homogenizer was employed to obtain a homogeneous mixture. The mixture was dropped to $500 \mathrm{~mL}$ of a gently agitated $2 \%$ calcium chloride solution (magnetic stirrer MIXdrive 6: 2 mag magnetic ${ }^{e}$ motion, Muenchen, Germany) via a $20 \mathrm{G}$ needle connected by a tube. A flow rate of $20 \mathrm{~mL} / \mathrm{min}$ was used by employing a peristaltic pump (PS-16 Sipper Pump, PG Instruments Limited, Leicestershire, UK). The obtained beads were separated by filtration using a sieve, washed with distilled water and dried at $50{ }^{\circ} \mathrm{C}$.

Table 6. Composition of pectin beads.

\begin{tabular}{ccccccccccc}
\hline Formulation & F1 & F2 & F3 & F4 & F5 & F6 & F7 & F8 & F9 & F10 \\
\hline $\begin{array}{c}\text { Natural } \\
\text { polymer }\end{array}$ & APN & APN & APN & APN & APN & APN & APN & APN & APN & APN \\
\hline $\begin{array}{c}\text { Synthetic } \\
\text { polymer }\end{array}$ & - & PA & PVP & AX & $\begin{array}{l}\text { PEG } \\
4000\end{array}$ & - & PA & PVP & AX & $\begin{array}{l}\text { PEG } \\
4000\end{array}$ \\
\hline $\begin{array}{c}\text { Active } \\
\text { substance }\end{array}$ & - & - & - & - & - & 5-ASA & 5-ASA & 5-ASA & 5-ASA & 5-ASA
\end{tabular}

APN—amidated pectin, PA-polyacrylic acid, PVP—kollidon, Polyvidone, Polyvinylpyrrolidone, Povidone, AX-Aristoflex, PEG—-polyethylene glycol, 5-ASA-5—aminosalicylic acid, mesalazine.

\subsection{Morphological Studies}

The diameters of beads F1-F10 before and after drying were obtained using a microscope (Motic SMZ-171, Xiamen, China) equipped with a digital camera (Moticam, Xiamen, China) connected to the computer with the software Motic Images Plus 2.0. The diameter of 100 beads was measured from the images by the software, and the mean values of the dry and wet diameters were calculated for each formulation. 


\subsection{FTIR Spectroscopy}

The FTIR spectra were recorded using a Thermo Scientific Nicolet iS50 FT-IR Spectrometer (Waltham, MA, USA) in the wavenumber range of $500-4000 \mathrm{~cm}^{-1}$. The pure components such as APN, 5-ASA, PA, PVP, AX and PEG 4000 as well as formulations F1-F10 and their corresponding physical mixtures were measured. The samples of formulations F1-F10 were measured in the wet state because the spectra of the dry beads F6-F10 were noisy.

\subsection{DSC Study}

The DSC study was carried out employing a differential scanning calorimeter (DSC 214 Polyma, Netzsch, Selb, Germany). The thermograms of the dry beads and 5-ASA as well as formulations F1-F10 and their corresponding physical mixtures were obtained. The DSC aluminum crucibles with an aluminum lid were filled with $3 \mathrm{mg}$ of sample. The measurements were conducted with a nitrogen flow rate of $50 \mathrm{~mL} / \mathrm{min}$ at a heating rate of $5^{\circ} \mathrm{C} / \mathrm{min}$ in the temperature range of $-10-300^{\circ} \mathrm{C}$.

\subsection{Release Studies}

The stability of pectin carriers F1-F5 was evaluated in $\mathrm{pH}=1.0,6.0$, and 7.4 with pectinase. The samples of millibeads were weighted and placed on the sieve which was introduced into a buffer of $\mathrm{pH}=1.0$ for $2 \mathrm{~h}$; the mass decrease was recorded every $15 \mathrm{~min}$-the samples were removed from the solution in defined time intervals, dried using paper towels and weighted. Afterwards, the millibeads were transferred to the buffer of $\mathrm{pH}=6.0$ for next $2 \mathrm{~h}$ and the same procedure was employed. Finally, samples were placed in the buffer $\mathrm{pH}=7.4$ with pectinase.

The release of 5-ASA from formulations F6-F10 was carried out using the dissolution basket apparatus 1 (Erweka DT126/128 light, Heusenstamm, Germany) with a rotation speed of $50 \mathrm{rpm}$ at a temperature of $37 \pm 0.5{ }^{\circ} \mathrm{C}$ [47]. The drug was released into $1 \mathrm{~L}$ of a $\mathrm{pH}=7.4$ buffer solution with $5 \mathrm{~mL}$ of added enzyme-pectinase to reflect the colon environment. The $3 \mathrm{~mL}$ samples were collected at appropriate time intervals within an 8-hour time period. The samples were replenished with $\mathrm{pH}=7.4$ buffer. All formulations were tested six times.

The UV-Vis spectra of 5-ASA in the $\mathrm{pH}=7.4$ buffer solution as well as in $2 \%$ calcium chloride solution were recorded employing a UV-Vis spectrophotometer (Jasco V-530, Tokyo, Japan) and are shown in Figure 8.

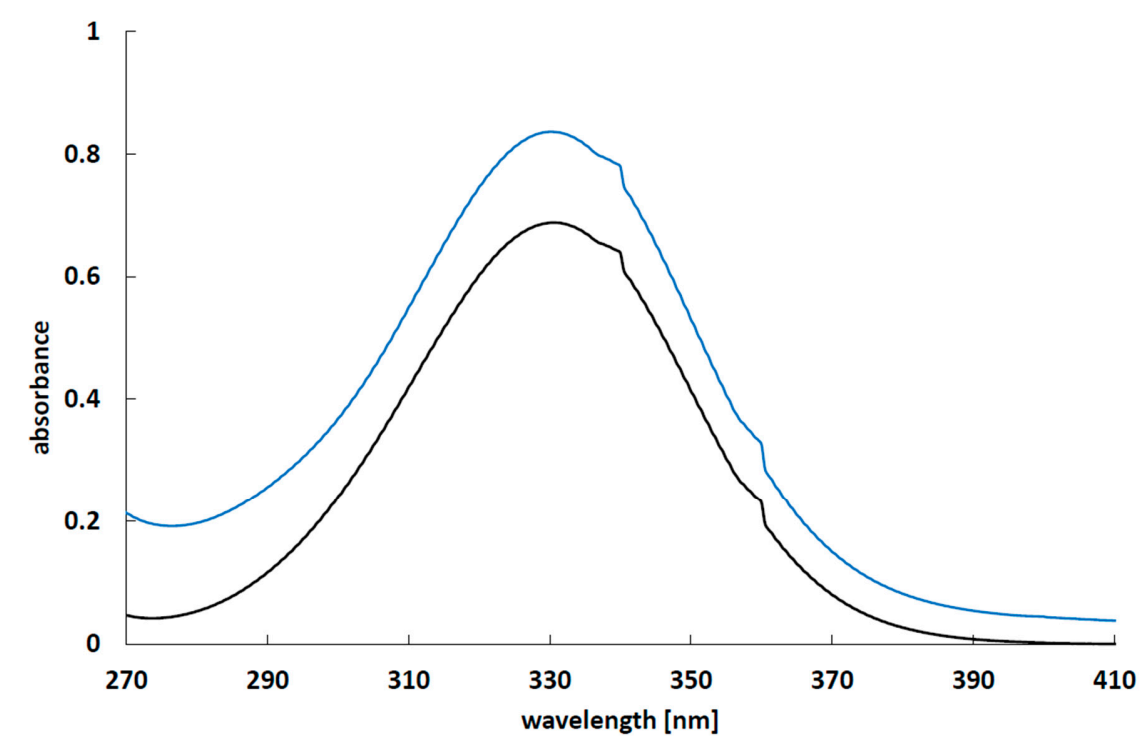

Figure 8. The UV-Vis spectrum of 5-ASA obtained at room temperature in buffer solution $\mathrm{pH}=7.4$, the concentration of 5 -ASA was $0.03 \mathrm{mg} / \mathrm{mL}$ (black line) and in $2 \%$ calcium chloride solution, the concentration of 5-ASA was $0.05 \mathrm{mg} / \mathrm{mL}$ (blue line). 
The absorbance of all samples was read at a wavelength of $330 \mathrm{~nm}$. At this wavelength, the absorbance maximum of 5-ASA in the buffer as well as that in the $2 \%$ calcium chloride solution were observed. The amount of the released 5-ASA (or the amount of the drug washed out to the calcium chloride solution from the beads) was calculated based on the prepared calibration curves. The obtained results were analyzed by zero-, first-, and second order kinetics and Higuchi [48], Korsmeyer-Peppas [48,49], and Hixon Crowell [50] models according to the equations shown in Table 7. The release parameters, including the release rate constants, the half-release time, and the diffusion coefficient $n$, were calculated. The correlation between the experimental data and the theoretical curve was described by the correlation coefficient value $\left(\mathrm{R}^{2}\right)$. Based on the value of $\mathrm{R}^{2}$, the appropriate kinetic models were selected.

Table 7. Kinetic equations used in the drug release analysis.

\begin{tabular}{cc}
\hline Kinetic Model & Equation \\
\hline Zero-order & $\mathrm{m}_{\mathrm{t}}=\mathrm{m}_{\mathrm{b}}+\mathrm{k}_{0} \mathrm{t}$ \\
\hline First-order & $\ln \left(\mathrm{m}_{0}-\mathrm{m}_{\mathrm{t}}\right)=\ln \left(\mathrm{m}_{0}\right)-\mathrm{k}_{1} \mathrm{t}$ \\
\hline Second-order & $\frac{1}{\left(\mathrm{~m}_{0}-\mathrm{m}_{\mathrm{t}}\right)}=\frac{1}{\mathrm{~m}_{0}}-\mathrm{k}_{2} \mathrm{t}$ \\
\hline Higuchi & $\mathrm{m}_{\mathrm{t}}=\mathrm{k}_{\mathrm{H}} \mathrm{t}^{0.5}$ \\
\hline Korsmeyer-Peppas & $\log \left(\frac{\mathrm{m}_{\mathrm{t}}}{\mathrm{m}_{\infty}}\right)=\log _{\mathrm{K}-\mathrm{P}}+$ nlogt \\
\hline Hixon-Crowell & $\mathrm{m}_{0}^{1 / 3}-\mathrm{m}_{\mathrm{rtnd}}{ }^{1 / 3}=\mathrm{k}_{\mathrm{H}-\mathrm{C}}$ \\
\hline
\end{tabular}

where $\mathrm{m}_{\mathrm{t}}$-the amount of the drug released during time $\mathrm{t} ; \mathrm{m}_{\mathrm{b}}$-the amount of the drug in the solution before the release, usually $0 ; \mathrm{k}_{0}$-the zero-order release rate constant; $\mathrm{m}_{0}$ - the amount of the drug in the formulation before the dissolution; $\mathrm{k}_{1}$ - the first-order release rate constant; $\mathrm{k}_{2}$ - the second-order release rate constant; $\mathrm{k}_{\mathrm{H}}$ - the Higuchi rate constant; $\mathrm{m}_{\infty}$ - the amount of the drug released after an infinitive time, $\mathrm{k}_{\mathrm{K}-\mathrm{P}}$ - the Korsmeyer-Peppas rate constant, $\mathrm{n}$ - the parameter indicative of the drug release mechanism; $\mathrm{m}_{\mathrm{rtnd}}$ - the amount of the drug retained in the formulation after time $\mathrm{t} ; \mathrm{k}_{\mathrm{H}-\mathrm{C}}$ - the Hixon-Crowell rate constant.

\subsection{The Difference Factor $f_{1}$, the Similarity Factor $f_{2}$}

The difference factor $\mathrm{f}_{1}$ and the similarity factor $\mathrm{f}_{2}$ were calculated as recommended by the FDA $[25,26]$ :

$$
\begin{gathered}
\mathrm{f}_{1}=\frac{\sum_{\mathrm{t}=1}^{\mathrm{n}}\left|\mathrm{R}_{\mathrm{t}}-\mathrm{T}_{\mathrm{t}}\right|}{\sum_{\mathrm{t}=1}^{\mathrm{n}} \mathrm{R}_{\mathrm{t}}} \times 100 \\
\mathrm{f}_{2}=50 \times \log \left\{\left[1+\frac{\sum_{\mathrm{t}=1}^{\mathrm{n}}\left(\mathrm{R}_{\mathrm{t}}-\mathrm{T}_{\mathrm{t}}\right)^{2}}{\mathrm{n}}\right]^{-0.5} \times 100\right\}
\end{gathered}
$$

where $\mathrm{n}$ is the number of time points, $R_{t}$ is the released value of the reference batch at time $t, T_{t}$ is the released value of the test batch at time $t$.

\subsection{Statistical Analysis}

One-way analysis of variance (ANOVA) with Tukey's test were employed to determine the significant differences between mean diameters of beads $(n=45)$.

The linearity of the kinetic models was carried out based on the least-squares regression method. The comparison of the correlation coefficient, $\mathrm{R}^{2}$, indicated the kinetic model that describes the observed processes well.

Statistical analysis of the release profiles was also conducted by ANOVA with Tukey's test. It was established that a variability between two dissolution profiles occurred for values of probability $\mathrm{p}$ lower than 0.5 [20]. 


\section{Conclusions}

In summary, the present study revealed that the incorporation of a synthetic polymer into pectin beads prolonged the release of the drug, particularly during the second stage of the release process. A spectroscopic analysis combined with a DSC study found that there may be an interaction between APN and the synthetic polymers that may affect the dissolution of the active substance. The inclusion of a synthetic polymer into pectin beads improved the strength of the calcium ion cross-linked network. Additionally, in some cases, the FTIR results suggested an interaction between 5-ASA and the polymer that may also influence the dissolution of the drug. The calculated values of the factors $f_{1}$ and $f_{2}$ confirmed a difference in the release of 5-ASA when a synthetic polymer was incorporated into the formulation.

Supplementary Materials: The following are available online, Figure S1: The microscopic images of all formulations studied, Figure S2: The DSC thermograms of F1 (green line), F6 (red line) and physical mixture of F6 (blue line), Table S1. The values of Tukey's HSD test obtained for the comparison of diameter wet beads $($ HSD $=0.146)$. Table S2: The values of Tukey's HSD test obtained for the comparison of diameter dry beads $($ HSD $=0.127)$, Table S3: The mean diameter of wet and dry beads of formulations F1-F10.

Author Contributions: Conceptualization, W.M. and D.W.-P.; methodology, D.W.-P. and W.M.; formal analysis, D.W.-P. and W.M.; investigation, D.W.-P., A.P. and W.M.; resources, W.M.; data curation, D.W.-P. and W.M.; writing-original draft preparation, D.W.-P.; writing—review and editing, W.M.; visualization, D.W.-P. and A.P.; supervision, W.M.; project administration, W.M. All authors have read and agreed to the published version of the manuscript.

Funding: The work was supported in the frames of a grant from Wroclaw Medical University and Ministry of Science and Higher Education, SUB.D060.20.003.

Acknowledgments: The study was partially performed on the research equipment of the Laboratory of Elemental Analysis and Structural Research in Wroclaw Medical University.

Conflicts of Interest: The authors declare no conflict of interest.

\section{References}

1. Martau, G.A.; Mihai, M.; Vodnar, D.C. The Use of Chitosan, Alginate, and Pectin in the Biomedical and Food Sector-Biocompatibility, Bioadhesiveness, and Biodegradability. Polymers 2019, 11, 1837-1865. [CrossRef]

2. Philip, A.K.; Philip, B. Colon targeted drug delivery systems: A review on primary and novel approaches. Oman Med. J. 2010, 25, 70-78. [CrossRef]

3. Coman, V.; Teleky, B.-E.; Mitrea, L.; Martau, G.A.; Szabo, K.; Calinoiu, L.-F.; Vodnar, D.C. Bioactive potential of fruit and vegetable wastes. Adv. Food Nutr. Res. 2020, 91, 157-225.

4. Sriamornsak, P.; Nunthanid, J. Calcium pectinate gel beads for controlled release drug delivery: I. Preparation and in vitro release studies. Int. J. Pharm. 1998, 160, 207-212. [CrossRef]

5. Assifaoui, A.; Chambin, L.O.; Cayot, P. Structure of calcium and zinc pectinate films investigated by FTIR spectroscopy. Carbohydr. Res. 2010, 345, 929-933. [CrossRef]

6. Munarin, F.; Tanzi, M.C.; Petrini, P. Advances in biomedical applications of pectin gels. Int. J. Biol. Macromol. 2012, 51, 681-689. [CrossRef] [PubMed]

7. Pan, D.; Zheng, X.; Zhang, Q.; Li, Z.; Duan, Z.; Zheng, W. Dendronized-Polymer Disturbing Cells' Stress Protection by Targeting Metabolism Leads to Tumor Vulnerability. Adv. Mater. 2020, 32, 1907490. [CrossRef] [PubMed]

8. Zhang, X.; Wu, Y.; Li, Z.; Wang, W.; Wu, Y.; Pan, D.; Gu, Z.; Sheng, R.; Tomás, H.; Zhang, H.; et al. Glycodendron/pyropheophorbide-a (Ppa)-functionalized hyaluronic acid as a nanosystem for tumor photodynamic therapy. Carbohydr. Polym. 2020, 247, 116749. [CrossRef] [PubMed]

9. Chen, K.; Liao, S.; Guo, S.; Zheng, X.; Wang, B.; Duan, Z.; Zhang, H.; Gong, Q.; Luo, K. Multistimuli-responsive PEGylated polymeric bioconjugate-based nano-aggregate for cancer therapy. Chem. Eng. J. 2020, 391, 123543. [CrossRef]

10. Iacucci, M.; Silva, S.D.; Ghosh, S. Mesalazine in inflammatory bowel disease: A trendy topic once again? Can. J. Gastroenterol. 2010, 24,127-133. [CrossRef]

11. Williams, C.; Panaccione, R.; Ghosh, S.; Rioux, K. Optimizing clinical use of mesalazine (5-aminosalicylic acid) in inflammatory bowel disease. Ther. Adv. Gastroenterol. 2011, 4, 237-248. [CrossRef] [PubMed] 
12. Aydìn, Z.; Akbuğa, J. Preparation and evaluation of pectin beads. Int. J. Pharm. 1996, 137, 133-136. [CrossRef]

13. Neufeld, L.; Bianco-Peled, H. Pectin-chitosan physical hydrogels as potential drug delivery vehicles. Int. J. Biol. Macromol. 2017, 101, 852-861. [CrossRef]

14. Kim, T.H.; Park, Y.H.; Kim, K.J.; Cho, C.S. Release of albumin from chitosan-coated pectin beads in vitro. Int. J. Pharm. 2003, 250, 371-383.

15. Voo, W.P.; Ravindra, P.; Tey, B.T.; Chan, E.S. Comparison of alginate and pectin based beads for production of poultry probiotic cells. J. Biosci. Bioeng. 2011, 111, 294-299. [CrossRef]

16. Jaya, S.; Durance, T.D.; Wang, R. Effect of alginate-pectin composition on drug release characteristics of microcapsules. J. Microencapsul. 2009, 26, 143-153. [CrossRef]

17. Auriemma, G.; Mencherini, T.; Russo, P.; Stigliani, M.; Aquino, R.P.; Gaudio, P.D. Prilling for the development of multi-particulate colon drug delivery systems: Pectin vs. pectin-alginate beads. Carbohydr. Polym. 2013, 92, 367-373. [CrossRef]

18. Atara, S.A.; Soniwala, M.M. Formulation and Evaluation of Pectin-Calcium Chloride Beads of Azathioprine for Colon Targeted Drug Delivery System. Int. J. Pharm. Pharm. Sci. 2018, 10, 172-179. [CrossRef]

19. Jackson, C.; Emeje, M.; Ofoefule, S. Ternary blends of some hydrophilic and hydrophobic polymers in colon targeted delivery of metronidazole. Jordan J. Pharm. Sci. 2015, 8, 51-58.

20. Costa, P.; Lobo, J.M.S. Modeling and comparison of dissolution profiles Paulo. Eur. J. Pharm. Sci. 2001, 13, 123-133. [CrossRef]

21. Shen, H.; Li, F.; Wang, D.; Yang, Z.; Yao, C.; Ye, Y.; Wang, X. Chitosan-alginate BSA-gel-capsules for local chemotherapy against drug-resistant breast cancer. Drug Des. Dev. Ther. 2018, 12, 921-934. [CrossRef] [PubMed]

22. Dash, S.; Murthy, P.N.; Nath, L.; Chowdhury, P. Kinetic modeling on drug release from controlled drug delivery systems. Acta Pol. Pharm. 2010, 67, 217-223. [PubMed]

23. Kruis, W.; Bar-Meir, S.; Feher, J.; Mickisch, O.; Mlitz, H.; Faszczyk, M.; Chowers, Y.; Lengyele, G.; Kovacs, A.; Lakatos, L.; et al. The optimal dose of 5-aminosalicylic acid in active ulcerative colitis: A dose-finding study with newly developed mesalamine. Clin. Gastroenterol. Hepatol. 2003, 1, 36-43. [CrossRef] [PubMed]

24. Safdi, M.A. Current Treatment Landscape of Mild-to-Moderate Ulcerative Colitis. Gastroenterol. Hepatol. 2010, 6, 5-6.

25. Bonnel, R.A.; Avigan, M.; Lyasu, S.; US Department of Health and Human Services Food and Drug Administration, Center for Drug Evaluation and Research. Guidance for Industry Dissolution Testing of Immediate Release Solid Oral Dosage Forms; US Department of Health and Human Services Food and Drug Administration: Rockville, MD, USA, 1997; pp. 15-22.

26. O'Hara, T.; Dunne, A.; Butler, J.; Devane, J. A review of methods used to compare dissolution profile data. Pharm. Sci. Technol. Today 1998, 1, 214-223. [CrossRef]

27. Mladenovska, K.; Cruaud, O.; Richomme, P.; Belamie, E.; Raicki, R.S.; Venier-Julienne, M.-C.; Popovski, E.; Benoit, J.P.; Goracinova, K. 5-ASA loaded chitosan-Ca-alginate microparticles: Preparation and physicochemical characterization. Int. J. Pharm. 2007, 345, 59-69. [CrossRef]

28. Hu, D.; Liu, L.; Chen, W.; Li, S.; Zhao, Y. A novel preparation method for 5-aminosalicylic acid loaded eudragit S100 nanoparticles. Int. J. Mol. Sci. 2012, 13, 6454-6468. [CrossRef]

29. Wójcik-Pastuszka, D.; Mazurek, K.L.; Szumny, A.J.; Alagöz, F.; Musiał, W.S. Properties of pectin based polymeric matrices for targeted drug delivery. Acta Pol. Pharm. Drug Res. 2017, 74, 1875-1885.

30. Alvarez-Gayosso, C.; Canseco, M.A.; Estrada, R.; Palacios-Alquisira, J.; Hinojosa, J.; Castano, V. Preparation and microstructure of cobalt(III) poly (acrylate) hybrid materials. Int. J. Basic Appl. Sci. 2015, 4, 255-263. [CrossRef]

31. Slavutsky, A.M.; Bertuzzi, M.A. Formulation and characterization of hydrogel based on pectin and brea gum. Int. J. Biol. Macromol. 2019, 123, 784-791. [CrossRef]

32. Nešić, A.; Onjia, A.; Davidovič, S.; Dimitrijevič, S.; Errico, M.E.; Santagata, G.; Malinconico, M. Design of pectin-sodium alginate based films for potential healthcare application: Study of chemico-physical interactions between the components of films and assessment of their antimicrobial activity. Carbohydr. Polym. 2017, 157, 981-990. [CrossRef] [PubMed]

33. Sawyer, L.; James, M.M.G. Carboxyl-carboxylate interactions in proteins. Nature 1982, 295, 79-80. [CrossRef] [PubMed] 
34. Morrill, J.A.; MacKinnon, R. Isolation of a single carboxyl-carboxylate proton binding site in the pore of a cyclic nucleotide-gated channel. J. Gen. Physiol. 1999, 114, 71-83. [CrossRef] [PubMed]

35. Langkilde, A.; Kristensen, S.M.; Leggio, L.L.; Mølgaard, A.; Jensen, J.H.; Houk, A.R.; Poulsen, J.-C.N.; Kauppinen, S.; Larsen, S. Short strong hydrogen bonds in proteins: A case study of rhamnogalacturonan acetylesterase. Acta Crystallogr. Sect. D Biol. Crystallogr. 2008, 64, 851-863. [CrossRef] [PubMed]

36. Brück, A.; McCoy, L.L.; Kilway, K.V. Hydrogen bonds in carboxylic acid-carboxylate systems in solution. 1. In anhydrous, aprotic media. Org. Lett. 2000, 2, 2007-2009. [CrossRef]

37. Song, Y.J.; Wang, M.; Zhang, X.Y.; Wu, J.Y.; Zhang, T. Investigation on the role of the molecular weight of polyvinyl pyrrolidone in the shape control of highyield silver nanospheres and nanowires. Nanoscale Res. Lett. 2014, 9, 17-25. [CrossRef]

38. Koczkur, K.M.; Mourdikoudis, S.; Polavarapu, L.; Skrabalak, S.E. Polyvinylpyrrolidone (PVP) in nanoparticle synthesis. Dalton Trans. 2015, 44, 17883-17905. [CrossRef]

39. Wu, Y.; De Liao, L.; Pan, H.C.; He, L.; Lin, C.T.; Tan, M.C. Fabrication and interfacial characteristics of surface modified Ag nanoparticle based conductive composites. RSC Adv. 2017, 7, 29702-29712. [CrossRef]

40. Hussien, M.A.; Essa, E.; El-Gizawy, S.A. Investigation of the effect of formulation additives on telmisartan dissolution rate: Development of oral disintegrating tablets. Eur. J. Biomed. Pharm. Sci. 2019, 6, 12-20.

41. Essa, E.A.; Elmarakby, A.O.; Donia, A.M.A.; Maghraby, G.M.E. Controlled precipitation for enhanced dissolution rate of flurbiprofen: Development of rapidly disintegrating tablets. Drug Dev. Ind. Pharm. 2017, 43, 1430-1439. [CrossRef]

42. Zhang, S.; Zhang, Y.; Liu, J.; Zhang, C.; Gu, N.; Li, F. Preparation of anti-sperm protein 17 immunomagnetic nanoparticles for targeting cell. J. Nanosci. Nanotechnol. 2008, 8, 2341-2346. [CrossRef] [PubMed]

43. Özgüney, I.; Shuwisitkul, D.; Bodmeier, R. Development and characterization of extended release Kollidon ${ }^{\circledR}$ SR mini-matrices prepared by hot-melt extrusion. Eur. J. Pharm. Biopharm. 2009, 73, 140-145. [CrossRef] [PubMed]

44. Shariare, M.H.; Sharmin, S.; Jahan, I.; Reza, H.M.; Mohsin, K. The impact of process parameters on carrier free paracetamol nanosuspension prepared using different stabilizers by antisolvent precipitation method. J. Drug Deliv. Sci. Technol. 2018, 43, 122-128. [CrossRef]

45. Büning, C.; Lochs, H. Conventional therapy for Crohn's disease. World J. Gastroenterol. 2006, 12, 4794-4806. [CrossRef] [PubMed]

46. Ahirrao, S.P.; Gide, P.S.; Shrivastav, B.; Sharma, P. Ionotropic Gelation: A Promising Cross Linking Technique for Hydrogels. J. Pharm. Nanotechnol. 2014, 2, 1-6.

47. European Pharmacopoeia-European Medicines Agency. European Pharmacopoeia 9.0. In Dissolution Test for Solid Dosage Forms; European Pharmacopoeia-European Medicines Agency: London, UK, 2017; pp. 302-309.

48. Siepmann, J.; Peppas, N.A. Higuchi equation: Derivation, applications, use and misuse. Int. J. Pharm. 2011, 418, 6-12. [CrossRef]

49. Korsmeyer, R.W.; Gurny, R.; Doelker, E.; Buri, P.; Peppas, N.A. Mechanisms of solute release from porous hydrophilic polymers. Int. J. Pharm. 1983, 15, 25-35. [CrossRef]

50. Hixon, A.W.; Crowell, J.H. Dependence of Reaction Velocity upon Surface and Agitation. Ind. Eng. Chem. 1931, 23, 923-931. [CrossRef]

Publisher's Note: MDPI stays neutral with regard to jurisdictional claims in published maps and institutional affiliations.

(C) 2020 by the authors. Licensee MDPI, Basel, Switzerland. This article is an open access article distributed under the terms and conditions of the Creative Commons Attribution (CC BY) license (http://creativecommons.org/licenses/by/4.0/). 